Kazan, E., C.-W. Tan, E. T. K. Lim, C. Sørensen, \& J. Damsgaard (Forthcoming):

Disentangling Digital Platform Competition: The Case of UK Mobile Payment Platforms. Journal of Management Information Systems

Special issue on Financial IS, Underlying Technologies, and the FinTech Revolution.

\title{
Disentangling Digital Platform Competition: The Case of UK Mobile Payment Platforms
}

\author{
Erol Kazan \\ Department of Digitalization, Copenhagen Business School \\ Howitzvej 60, 2000 Frederiksberg, Denmark \\ eka.digi@cbs.dk \\ Chee-Wee Tan \\ Department of Digitalization, Copenhagen Business School \\ Howitzvej 60, 2000 Frederiksberg, Denmark \\ ct.digi@cbs.dk
}

Eric T.K. Lim

School of Information Systems \& Technology Management, UNSW Business School, UNSW Sydney

High St, Kensington, NSW 2052, Australia

e.t.lim@,unsw.edu.au

Carsten Sørensen

Department of Management, London School of Economics and Political Science

Houghton Street, London WC2A 2AE

c.sorensen@1se.ac.uk

Jan Damsgaard

Department of Digitalization, Copenhagen Business School

Howitzvej 60, 2000 Frederiksberg, Denmark

jd.digi@,cbs.dk

Last revised: November 26, 2017

\begin{abstract}
Digital platforms confer competitive advantage through superior architectural configurations. There is however still a dearth of research that sheds light on the competitive attributes which define platform competition from an architectural standpoint. To disentangle platform competition, we opted for the mobile payment market in the United Kingdom (UK) as our empirical setting. By conceptualizing digital platforms as layered modular architectures and embracing the theoretical lens of strategic groups, this study supplements prior research by deriving a taxonomy of platform profiles that is grounded on the strategic dimensions of value creation and value delivery architectures. We discover that mobile payment platforms could be delineated based on whether they are: (1) integrative or integratable on their value creation architecture; and (2) have direct, indirect, or open access on their value delivery architecture. The preceding attributes of value creation architecture and value delivery architecture aided us in identifying six profiles associated with mobile payment platforms, which in turn led us to advance three competitive strategies that could be pursued by digital platforms in network economies.
\end{abstract}

Keywords: Competition, digital infrastructures, digital platforms, financial technologies, mobile payments, network economies, strategic groups 


\section{INTRODUCTION}

The platformization of digital goods and services is a growing trend in many industries. Digital platforms [16] (hereafter platforms) are layered modular information technology (IT) architectures [74, 80] embedded within business networks $[2,66]$. Within these business networks, platforms function as innovation hubs in offering services (e.g., payments) that emphasize mediation and modularity $[68,80]$. Platform owners (e.g., Apple) and platform complementors (e.g., developers) collaborate to develop respective firm-specific components to co-create valued platform derivatives ${ }^{1}$ (e.g., apps) [20, 27, 62]. Because platforms constitute a vital source of competitive advantage within networked economies, there has been an enduring stream of research that examines how platforms effectively compete $[7,8$, 60]. Scholars have attested to the criticality of matching mechanisms (e.g., pricing) in attracting and retaining stakeholders. A core premise of these studies is that successful platforms must induce positive and sustainable network effects to appeal to stakeholders. In the same vein, platformization has revolutionized the financial service industry by altering the manner through which value is created and delivered. Emerging technologies in the likes of blockchain and cryptocurrency have displaced conventional modes of transactions (e.g., centralized payment networks controlled by market incumbents) by introducing alternative value creation and delivery architectures that function as open, decentralized peerto-peer (P2P) platforms. This in turn compels market incumbents to redesign their financial service offerings to harness the benefits of platformization and remain competitive within networked economies.

Yet, despite the disruption brought about by platformization, we have limited knowledge of how digital platforms compete from an architectural standpoint [5]. Responding to calls for an in-depth appreciation of the impact of architectural configurations on digital platform competition [5], we draw on previous literature on interfirm competition. Specifically, we espouse the theoretical lens of strategic groups to unpack the dimensions upon which interfirm rivalries are built $[18,44]$. Research has delineated and clustered firms into strategic groups to account for their competitive dynamics. Past studies hold that firms belonging to the same strategic group possess comparable competitive attributes, and thus, compete more fiercely with group members (intragroup competition) than with members from another strategic group (intergroup competition). By embracing the theoretical lens of strategic groups, we aim to contribute to an in-depth appreciation of how different platform-driven strategic groups configure their technological architectures to bolster their competitiveness.

The mobile payments market in the United Kingdom (UK) is highly mature and competition is driven primarily by advances in financial technology - fintech innovation - among incumbents and contenders. Long-standing relationships among market incumbents and costly access to established payment infrastructures have compartmentalized competition by forcing select players to band together to compete with incumbents. The fragmentation of the UK mobile payments market into competing factions hence conforms to the classical conception of strategic groups, and serves as an excellent empirical context for our investigation into digital platform competition. Through case studies of multiple mobile payment platforms in the UK market, we strive to provide answers to two research questions: What are the strategic attributes that define platform competition from an architecture standpoint? What are generic platform strategies within networked economies?

This study contributes to a deeper understanding of how digital financial services such as mobile payments are leveraging on platform design to revolutionize their strategies within a regulated market environment. Synthesizing prior research, we identify two distinct strategic dimensions of digital platform competition: (1) value creation architecture, and; (2) value delivery architecture. In turn, the configuration of these two strategic dimensions shape the strategic orientation of platforms in the market. Our analysis generated six discrete platform profiles, each exemplified by a corresponding mobile payment service that seeks to revolutionize its offerings. The profiles serve as the basis on which to unravel

\footnotetext{
${ }^{1}$ We employ the term platform derivatives to describe technological by-products of digital platforms that are constructed on the basis of developmental tools (e.g., application programming interfaces (APIs) or software development kits (SDKs)) supplied by these platforms.
} 
digital platform competition. Our findings further reveal that these six platform profiles translate into three distinct platform strategies, each with its own merits and shortcomings.

\section{THEORETICAL FOUNDATION}

\subsection{Overview of Literature on Mobile Platforms}

Research into mobile payments has received substantial attention among scholars in their bid to explain the logic behind how mobile payment service providers innovate and compete $[14,32,50]$. Indeed, most mobile payment studies are centered on attempts to illuminate the drivers of service adoption [63], such as: exploring the cooperative and competitive dynamics among mobile payment providers within industries $[17,32]$; prescribing the strategic design of mobile payment platforms/services towards market ignition [49]; revealing the challenges of creating a mobile payments market in the first place [50]; or scrutinizing the potential of novel mobile payment technologies (e.g., near field communication (NFC)) $[15,48]$. A common theme among these studies is that they largely treat the external market as their unit of analysis (e.g., multi-sided platform perspective), thereby constraining our knowledge of how mobile payment platforms compete from an architectural standpoint. Past studies of digital platforms hint that such platforms achieve competitiveness through superior architectural configurations that are less susceptible to replication [51].

Arguably, one way of comprehending digital platform competition is to theoretically dissect such platforms into layered modular technology architectures [80]. We contend that competitive mobile payment platforms embody differentiated architectural configurations that mirror their strategic orientation. In turn, these strategic orientations in conjunction with their matching architectural configurations translate into distinct platform strategies, which when combined, form the basis for competition within the mobile payments market. We hence turn to the research stream on strategic groups as an appropriate theoretical lens for characterizing digital platform competition in the mobile payments market.

\subsection{Strategic Groups: An Overview}

Scholars have employed strategic groups as a theoretical lens [44] to uncover why certain firms in the same industry perform better than their rivals. The term strategic groups was first coined by Hunt [35] to explain firm competition in the home appliance industry. Firms belonging to the same strategic group exhibit similar competitive attributes and market orientations, they differ from those strategic groups that target other segments of the same industry [44, 70]. Porter [56, p. 129] proposed a more granular view on strategic groups, describing them as a "group of firms in an industry following the same or a similar strategy along the strategic dimensions". The methods by which firms compete are heterogeneous, as varying emphases are placed on different competitive attributes.

To derive strategic groups, scholars applied a myriad of competitive attributes, which include: available resources (e.g., distribution channels, assets, and technology) [6, 12, 45]; cognitive factors (e.g., top management perception, reputation, and identity) [24, 52, 58]; or economic conditions (e.g., product/service portfolio, firm performance and size, sales, margin, profit, and market share) [25, 42, 65]. Past studies further indicated that firms' dynamic capabilities can solidify the barriers of strategic groups [40,69]. Yet, despite extensive research on strategic groups, previous work has centered on traditional industries and largely ignored firms situated in networked economies such as platformdriven market environments.

\subsection{Strategic Groups within Industrialized Economies}

Porter [56] claimed that firms' affiliation with strategic groups stems from having control over limited resources. By belonging to the same strategic group, members can install mobility barriers to preclude other firms from entering, or discouraging member firms from leaving the group at will [28]. Mobility barriers reflect segregation strategies adopted by strategic group members to designate and enforce conditions of loyalty through controlling member firms' access to exclusive shared resources.

Past studies suggest that competitive attributes underlying mobility barriers are typically idiosyncratic to the industry $[44,56]$. Mascarenhas and Aaker's [43] work on the oil-drilling industry suggests that competitive attributes in one industry (e.g., offshore drilling capabilities) may not be applicable to others. The study by Mehra [45] in the US banking sector revealed that configurations of industry-specific 
resources also constitute definitive attributes of strategic groups. Mehra [45] noted that the ownership of strategic resources, by itself, does not necessarily generate competitive benefits, countering instead that optimal "configurations of [strategic] resources" are necessary to unlock their full potential. In light of the abovementioned studies, we contend that strategic groups are mainly shaped by industry specific resources and that the composition and configuration of these resources serve as the foundation for how firms within a given industry compete with one another.

\subsection{Strategic Groups within Networked Economies}

Increasingly, firm competition is driven by networked business logics in which strategic linkages are forged among multiple firms to pool complementary capabilities and resources to augment one another's products and services $[4,13,19,30]$. The motivation for firms is to build up sustainable competitive advantage that is grounded in valuable, rare, and inimitable joint resources [cf. 13]. Gulati et al. [30] argued that a firm's network, comprising a set of strategic linkages, constitutes its own inimitable firm resource because they are rooted in complex managerial processes and difficult to replicate [4]. Within the automotive industry, Nohria and Garcia-Pont [47] maintained that strategic linkages among automakers (e.g., joint ventures) form an indispensable competitive resource, as they circumvent certain resource constraints (e.g., patents), and other organizational shortcomings. This aids firms in overcoming entry barriers installed by existing or emerging strategic groups. Accordingly, firms, which lack industry-specific resources, can forge linkages with other firms to compensate for their own organizational deficiencies. Similarly, in networked economies where firms are intricately connected, access or control over strategic linkages is a valuable resource [cf. 30, 53].

Beyond having access to strategic linkages, the configuration of such strategic linkages is equally important for realizing the potential of interfirm relationships [23, 45, 51]. Configuration is the purposeful arrangement and combination of functional elements to generate a desired output [23]. Similar to the notion of combinative capabilities [37, p. 508] where firms compete through "new resource combinations [i.e. configurations] that are rare, valuable, hardly imitable, and non-substitutable", firms purposely combine and (re)configure firm linkages to create valued market outputs. Possessing dynamic capabilities, which reflect one's "ability to integrate, build, and reconfigure internal and external competences" [69, p. 516], firms with access to strategic linkages respond to market changes by reconfiguring or even terminating existing strategic linkages with other firms. The study by Pagani [51] in the multi-media industry supports the notion of network orchestration. Pagani [51, p. 629] postulates that "as modularization takes hold, the ability to coordinate among the modules will become the most valuable business skill". Strategic linkages and configurations are synonymous with interfirm modularity [68], where multiple platformized firms supply buildings blocks and components to create modularized goods and services within digitalized value networks $[2,80]$.

\subsection{Digital Platform Competition}

Extant literature has explored how platforms compete with one another from three perspectives, namely, product, multi-sided, and ecosystem [71]. From a product platform perspective [36, 38], competitiveness is achieved by controlling a stable platform core that acts the technological foundation for a family of platform derivatives. Firms with product platforms usually compete through economies of scale and scope, which are realized based on innovation of the core and peripheries. Originating from industrial economics, the multi-sided platform perspective $[39,41,60]$ holds that competitive platforms embody positive networks effects whereby the value of a platform depends on the population and growth of distinguishable users (e.g., buyers and sellers on Amazon). Studies belonging to this research stream focuses on identifying efficient matching mechanisms (e.g., pricing) to entice and galvanize users against rival platforms. Finally, the platform ecosystem perspective places emphasis on the composition and configuration of technological components. Platforms in possession of superior technological components and configurations are deemed to be competitive in the marketplace $[9,10]$ because they tend to produce favorable conditions for soliciting contributions from third parties (e.g., external developers), thereby culminating in positive network effects.

Prior research on platform competition within the payment industry has largely subscribed to the multisided platform perspective $[11,59]$. Beyond a few exceptions from the computer or software industry $[9,10]$, there is a paucity of studies that shed light on how platforms compete from a technological 
viewpoint in highly regulated industries such as that of the mobile payments market.

\subsection{Digital Platforms}

Digital platforms are layered modular technology architectures within business networks $[54,74,80]$. Within these business networks [3], platforms can orchestrate technological components to foster coinnovation with cooperative stakeholders, who might also be competitors among themselves [5, 51]. Additionally, platforms can house competitors within the same platform stack (e.g., Amazon and Apple) [80]. From the above description, it is thus conceivable that digital platforms resemble the technological manifestations of interfirm strategic linkages within networked economies. We therefore build on past studies about platform ecosystems to elicit determinants of digital platform competition that correspond to the modular composition (similar to strategic linkages) of such platforms as well as their configurations (similar to strategic linkage configurations).

Value Creation Architectures: The first strategic dimension of digital platform competition lies in the modular composition or strategic linkages among stakeholders in a network. Simply put, platforms supply the technical foundation for third parties (e.g., external developers) to develop complementary platform derivatives (e.g., iOS apps) on separate layers of a platform (e.g., service layer) [80]. In so doing, platform owners (e.g., Apple) leverage on boundary resources (e.g., APIs) [20, 27] to channel the creativity of network members towards the development of value-added derivatives. Because platforms supply developmental tools (or building blocks) for other platform members, an enduring challenge for platform owners is governance. Platform owners are constantly challenged to enforce control and support generativity (i.e., unprompted changes by heterogeneous audiences) [81], while ensuring reciprocal value appropriations $[22,73,77]$. Platforms have the (business) logic of transforming resources into valuable market outputs. In this regard, platforms compete within value networks by offering the best resource configuration (i.e., stable core and flexible derivatives) with the greatest added value. We hence define value creation architecture as modular components of a digital platform that can be exploited by third parties to develop value-added derivatives.

Value Delivery Architectures: The second strategic dimension of digital platform competition stems from the configuration of strategic linkages among stakeholders belonging to a value network. In other words, for platforms to efficiently diffuse derivatives across their value network, they rely on access to technological backbones in the form of digital infrastructures (e.g., Internet) [31, 33, 67, 72]. Hanseth and Lyytinen [31, p. 4] conceive digital infrastructures "as a shared, open ...heterogeneous, and evolving socio-technical system ... of [IT] capabilities". Likewise, Henfridsson and Bygstad [33, p. 908] equate digital infrastructures with "the collection of technological and human components, networks, systems, and processes that contribute to the functioning of an information system". Conversely, Tilson, et al. [72, p. 748] define digital infrastructures as "basic information technologies and organizational structures, along with the related services and facilities necessary for an enterprise or industry to function". Consistent with the preceding theorizations, we define value delivery architecture as omnipresent digital infrastructures that operate as technological backbones of value networks to facilitate the efficient delivery of standardized platform derivatives among stakeholders belonging to the same value network. One can see from our definition that the motivation behind why digital platforms strive for unimpeded access to digital infrastructures is to streamline the delivery of platform derivatives. Digital platforms lacking access to digital infrastructures, especially when these infrastructures are dominant and exclusive, will be compelled to either: (1) forge linkages with other firms that have access; or (2) utilize alternate access options that replicate established infrastructures.

Platforms within network economies vary in their modularity and, by extension, compete on two strategic architectural dimensions: namely (1) value creation, and; (2) value delivery (see Figure 1). Specifically, platforms practice modularity on their value creation architectures (i.e., platform level) to (co)create value-added derivatives. Likewise, platforms also practice modularity on value delivery architectures (i.e., infrastructure level) to deliver derivatives in a standardized format. We posit that platforms exhibiting similar attributes along these two strategic dimensions should share identical competitive instincts, and belong to the same strategic group (or platform profile). 


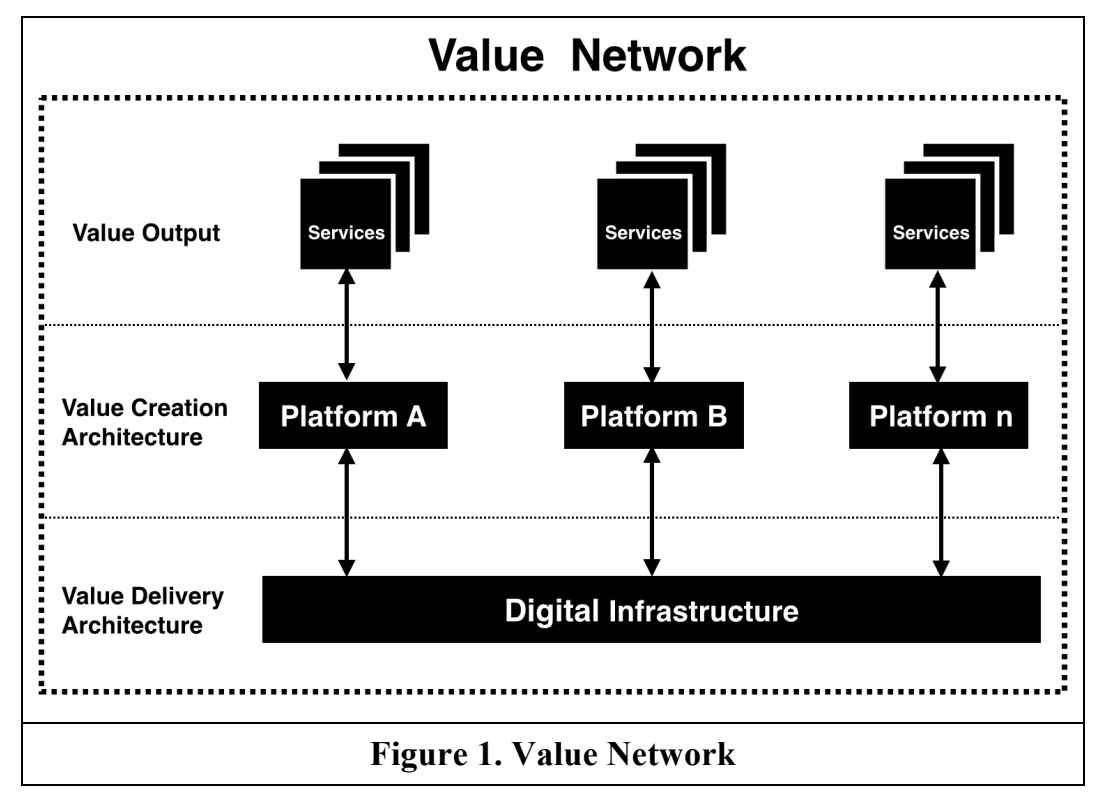

\section{METHODOLOGY}

This study adopts an interpretive multiple case study approach to uncover competitive attributes that give rise to distinct platform-driven strategic groups (or platform profiles) [76, 79]. In this sense, we blend both exploratory (i.e., Theory I) and explanatory (i.e., Theory II) approaches [29] by synthesizing focal concepts from extant literature on platform and strategic groups to craft an analytical lens for: (1) identifying competitive attributes pertinent to platforms from an architectural standpoint; (2) deriving formal classifications of platform profiles, as well as; (3) disentangling how value creation, delivery, and competition unfold among these platform profiles. We deem the case study approach to be an appropriate method of inquiry as it can answer both "how" and "why" questions in complex and nebulous research environments [79], a setting similar to the context of this study. Through an analysis of key actors within the UK mobile payments market, we seek to untangle the intertwining relationship between technological architectures and the competitive strategies pursued by these platform profiles.

\subsection{Research Setting: Mobile Payments Market in the United Kingdom (UK)}

Payment is an indispensable service within national economies. To guarantee secure and reliable payment services for an entire country, access to established payment infrastructures is subjected to stringent and costly regulatory oversight. In this light, access to established payment infrastructures can be deemed to be an asset within the payment industry. To unravel the competitive attributes governing different platform profiles, we turn to the UK mobile payments market as our empirical context. The UK payments industry is in the midst of market convergence and transformation. Regulatory changes, falling transaction costs, and intensifying competition have culminated in the gradual deconstruction of once vertically integrated financial institutions (e.g., banks) by permitting new actors to enter the industry by disintermediating once lucrative value streams. Under this broader context, mobile payments have emerged as one of the most competitive market spaces in the payment industry.

Due to massive growth opportunities in the mobile payments market, new payment providers are encroaching on territories that are held by market incumbents. Payment instruments have evolved from simplistic plastic payment cards to sophisticated digital payment applications that are installed on consumers' mobile devices. These mobile payment platforms move value between payers and payees in a digitized fashion, which in turn pose a threat to the payment incumbents (e.g., banks) that have traditionally occupied this space. These new mobile payment platforms could foster new consumption habits and decouple long-standing customer relationships with incumbents. To compete, payment incumbents are compelled to launch their own mobile payment solutions (e.g., Barclay's Pingit) as a preemptive measure to maintain their relevance to existing customers. 
Apart from the disruption brought on by emergent technologies, regulatory changes have also intensified market competition. UK payment regulators have called on incumbent payment scheme owners (e.g., Faster Payments ${ }^{2}$ ) to offer new payment providers non-discriminatory access to established payment infrastructures. These regulatory changes have enabled the new payment providers to interface their platforms with established payment infrastructures when moving value between payers and payees. Though the abovementioned regulatory changes are likely to accelerate competition among payment actors in the UK mobile payments market, there is notably little knowledge of how mobile payment providers, as owners of digital platforms, compete from an architectural standpoint.

\subsection{Case Selection: Six Distinct Platform Profiles}

To derive distinct platform profiles within the UK mobile payments market, 16 semi-structured interviews were carried out with five industry experts and 11 financial institutions offering mobile payment services. We began by conducting five semi-structured interviews with UK payment industry experts who are well-acquainted with the industry due to their unique position in the midst of the shake up in the fintech landscape (see Table 1). These initial interviews allow us to construct an overview of the UK payment industry and glean insights into the: (1) roles of key actors (e.g., banks, payment start-ups, acquirers or merchants' bank, technology providers, payment infrastructure owners, and credit card firms) operating in the industry; as well as (2) explicit and implicit mechanisms underlying competition among these actors.

\begin{tabular}{|c|c|c|c|c|}
\hline \multirow{2}{*}{ Financial Institution } & \multirow{2}{*}{\multicolumn{2}{|c|}{$\begin{array}{c}\text { Table 1. Breakdown of Data Sources } \\
\text { Primary Data }\end{array}$}} & \multirow{2}{*}{\multicolumn{2}{|c|}{ Secondary Data }} \\
\hline & & & & \\
\hline \multicolumn{5}{|l|}{ Industry Experts } \\
\hline Berenberg & VP / Equity Analyst on Financial Technology & 61 mins & - & - \\
\hline IBM & Executive Architect, Banking and Financial Markets & 72 mins & - & - \\
\hline Consult Hyperion & Director of Innovation & 48 mins & - & - \\
\hline Vocalink & Strategy Lead & 125 mins & - & - \\
\hline AMEX & Mobile Product Innovation and Strategy & 153 mins & - & - \\
\hline \multicolumn{5}{|l|}{ Banking Institutions } \\
\hline \multirow[t]{2}{*}{ Barclays (Pingit) } & \multirow[t]{2}{*}{ SVP of Mobile Solutions } & \multirow[t]{2}{*}{66 mins } & Finextra.com & 120 \\
\hline & & & Thepaypers.com & 10 \\
\hline Blockchain.info & Co-Founder & 82 mins & Finextra.com & 2 \\
\hline CEX.io & Chief Information Officer (CIO) & 45 mins & Thepaypers.com & 2 \\
\hline Circle & Chief Executive Officer (CEO) & 45 mins & Finextra.com & 13 \\
\hline CryptoPay & Founder & $112 \mathrm{mins}$ & Thepaypers.com & 1 \\
\hline Droplet & Chief Technology Officer (CTO) & $68 \mathrm{mins}$ & Thepaypers.com & 2 \\
\hline Google Wallet & Head of Europe, the Middle East and Africa & 65 mins & Thepaypers.com & 21 \\
\hline \multirow[t]{2}{*}{ HSBC } & \multirow[t]{2}{*}{ Global Head of Mobile Payment } & \multirow[t]{2}{*}{85 mins } & Finextra.com & 39 \\
\hline & & & Thepaypers.com & 1 \\
\hline \multirow[t]{2}{*}{ Paym } & \multirow[t]{2}{*}{ Head of Development } & \multirow[t]{2}{*}{65 mins } & Finextra.com & 47 \\
\hline & & & Thepaypers.com & 8 \\
\hline \multirow[t]{2}{*}{ Santander } & \multirow[t]{2}{*}{ Innovation Analyst } & \multirow[t]{2}{*}{210 mins } & Finextra.com & 29 \\
\hline & & & Thepaypers.com & 1 \\
\hline \multirow[t]{2}{*}{ Zapp } & \multirow[t]{2}{*}{ Chief Executive Officer (CEO) } & \multirow[t]{2}{*}{44 mins } & Finextra.com & 71 \\
\hline & & & Thepaypers.com & 10 \\
\hline Total & 16 interviews & 1,346 mins & 2 sources & 377 articles \\
\hline
\end{tabular}

From the expert interviews, we selected 11 UK financial institutions, which have been touted by the industry experts as revolutionary players in the mobile payments market, to serve as case companies for our study. Additional semi-structured interviews were conducted with representatives from these 11 financial institutions. Furthermore, to accurately position the 11 financial institutions within the UK payment industry landscape and authenticate claims made by the interviewees, we also gathered data from secondary sources (see Table 1). Guided by our analytical framework (see Figure 1), we inspected

${ }^{2}$ Faster Payments Service (FPS) is a UK banking initiative to reduce payment times between customer bank accounts from three working days, which transfers usually take via the long-established BACS system, to typically a few hours. 
the 11 cases with respect to the two strategic dimensions of value creation and value delivery architectures. Our goal is to comprehend how these case companies design their respective mobile payment services to: (1) create value through co-innovation, and; (2) deliver value through access to established payment infrastructures. From the analysis of the 11 cases, six distinct platform profiles (or platformbased strategic groups) surfaced according to attributes delineated across the strategic dimensions of value creation and delivery architecture. From our case pool, we present the six most prominent instantiations corresponding to each platform profile.

These six illustrative cases of mobile payment services are either operated by incumbent financial institutions or owned by market leaders in the payment industry, namely: (1) Pingit (Barclays); (2) Droplet (payment start-up); (3) Paym (collaborative payment solution devised by consortium of UK banking institutions); (4) Zapp (Vocalink, a payment technology provider); (5) Blockchain.info (blockchain start-up), and; (6) Circle (blockchain start-up). To capture novel fintech actors that differ significantly in their technological approach to payment processing, we have opted to include two blockchain startups. Blockchain is an emerging technology for digital value transfer (e.g., payment systems) that replicates the functionalities of established payment infrastructures. We selected two pervasive blockchain start-ups: Blockchain.info and Circle. Both startups leverage on the Bitcoin blockchain technology to transfer digital value (i.e., Bitcoins) among payers and payees. Whereas end users of Blockchain.info have to convert Bitcoins into fiat currency (e.g., British pounds) via a third party (e.g., Bitcoin exchange), their counterparts in Circle can perform direct conversion between Bitcoins and fiat currency. We chose these blockchain companies because they not only operate in the UK, they are also recognized as global leaders with respect to the level of venture capital investment garnered and the size of their user base. Besides, Circle is the first Bitcoin startup in the world to be granted an e-money license by UK regulators, thereby enabling the company to form sustainable banking relationships and negotiate access to established payment infrastructures [55].

\subsection{Data Collection}

Data for this study were gathered from two sources: 16 semi-structured interviews and secondary archival records (see Table 1). Semi-structured interviews have the advantage of permitting the interviewer to glean extra insights (e.g., publicly inaccessible data) that may enrich the study further. The interview protocol was devised in accordance with our analytical framework and contained questions that have been formulated to unravel the mechanisms underpinning how each of the 11 mobile payment services works in practice. Specifically, when interviewing representatives from the 11 financial institutions, we not only asked them to reconstruct both narratively and visually how a typical transaction could be executed on their respective mobile payment platforms, but we also probed them on the identity of external partners who are instrumental in supplying the necessary capabilities and resources to generate the service offering. All semi-structured interviews were recorded and subsequently transcribed for coding purposes. Apart from the interviews, we also distilled the product pages of the 11 mobile payment platforms together with payment reports, white papers, and press releases from industry associations (e.g., the European and UK Payments Council) as well as online news outlets (e.g., Finextra.com) and news aggregators (i.e., ThePaypers.com) reporting on the payment industry (see Table 1). Through the collection of data from secondary sources, we can triangulate insights gleaned from interviews with events documented in the public domain.

For detailed presentation of the six illustrative fintech cases of mobile payment services, we draw primarily on interviews conducted with the: (1) Senior Vice President (SVP) of Mobile Solutions at Barclays to shed light on Pingit; (2) Chief Executive Officer (CEO) of Zapp; (3) Head of Development at Paym; (4) Chief Technology Officer (CTO) of Droplet; (5) Co-Founder of Blockchain.info, and; (6) CEO of Circle, as well as secondary archival records that have been extracted for each service. 


\subsection{Data Analysis}

The analysis of the empirical data was performed in three steps: (1) industry analysis, (2) intra-case analysis, and; (3) inter-case analysis. Table 2 gives a synopsis of how interview quotes were coded in accordance with content analytical techniques.

\begin{tabular}{|c|c|c|c|c|}
\hline \multicolumn{2}{|c|}{ Dimension } & Exemplary Quote & Intra-Case Analysis & Inter-Case Analysis \\
\hline \multirow{2}{*}{ 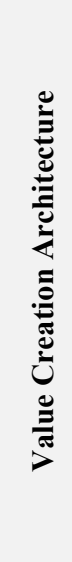 } & 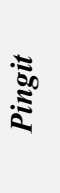 & $\begin{array}{l}\text { Quote 1: It has to be, of course, then commercially } \\
\text { relevant to be disclosing any API's to that party... it's } \\
\text { very much about providing information into, or to, } \\
\text { the Pingit app as opposed to integrating Pingit into } \\
\text { another app, for example. }\end{array}$ & $\begin{array}{l}\text { Pingit is moderating plat- } \\
\text { form access such that co- } \\
\text { creation value streams are } \\
\text { inwards and orientated to- } \\
\text { wards the platform. }\end{array}$ & \multirow{2}{*}{$\begin{array}{l}\text { Whereas Pingit maintains } \\
\text { stringent control over the } \\
\text { ability of external devel- } \\
\text { opers to develop value- } \\
\text { added derivatives on its } \\
\text { mobile payment platform, } \\
\text { Paym practices the oppo- } \\
\text { site. Consequently, Pingit } \\
\text { competes by ensuring the } \\
\text { consistency and quality of } \\
\text { its service offerings while } \\
\text { Paym competes by mobi- } \\
\text { lizing third parties to en- } \\
\text { gage in co-innovation. }\end{array}$} \\
\hline & 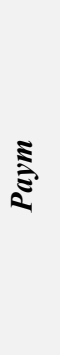 & $\begin{array}{l}\text { Quote 2: [Paym] facilitates payments but it doesn't } \\
\text { do payments itself directly. } \\
\text { Quote 3: The way the service works, assuming you } \\
\text { and I both registered through our banks, I would log } \\
\text { into my mobile banking application, I would select } \\
\text { the Paym option and then I can send money to you by } \\
\text { sending it to your phone number } \\
\text { Quote 4: It's an extension of the functionality that a } \\
\text { banking app that I have on my phone offers me. }\end{array}$ & $\begin{array}{l}\text { Paym shares its platform } \\
\text { with third parties such } \\
\text { that the co-creation value } \\
\text { streams are reciprocal in } \\
\text { nature. }\end{array}$ & \\
\hline \multirow{2}{*}{ 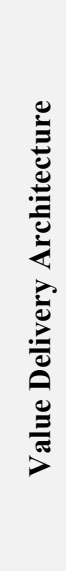 } & 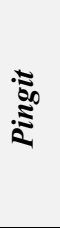 & $\begin{array}{l}\text { Quote 5: when we use the Faster Payment infrastruc- } \\
\text { ture we as, of course, is one of the founders of the } \\
\text { Faster Payments infrastructure we have connectivity } \\
\text { into the Payments Councils Faster Payments product. }\end{array}$ & $\begin{array}{l}\text { Barclays, as the owner of } \\
\text { Pingit and co-owner of } \\
\text { the Faster Payments pay- } \\
\text { ment infrastructure, has } \\
\text { direct access to send and } \\
\text { receive payments in UK. }\end{array}$ & \multirow{2}{*}{$\begin{array}{l}\text { Both Pingit and Paym has } \\
\text { direct access to an estab- } \\
\text { lished payment infrastruc- } \\
\text { ture by virtue of their par- } \\
\text { ent financial institution. } \\
\text { Consequently, competi- } \\
\text { tive differentiation be- } \\
\text { tween Pingit and Paym is } \\
\text { hard to achieve in terms } \\
\text { of their value delivery ar- } \\
\text { chitecture. }\end{array}$} \\
\hline & 胥 & $\begin{array}{l}\text { Quote 6: Faster Payments is the UK's real-time ac- } \\
\text { count-to-account transfer banking [infrastructure], } \\
\text { Paym is a way of driving more transactions through } \\
\text { that banking [infrastructure]. } \\
\text { Quote 7: I'm then providing my bank with the in- } \\
\text { struction to make a payment and that payment will ei- } \\
\text { ther go through Faster Payments or it will go } \\
\text { through Link and those are the two approved, two } \\
\text { supported, payment schemes in this service. }\end{array}$ & $\begin{array}{l}\text { Paym has direct access to } \\
\text { an established value de- } \\
\text { livery architecture. }\end{array}$ & \\
\hline
\end{tabular}

- Industrial Analysis: After a careful review of the primary and secondary dataset, the first author reconstructed the empirical landscape to derive an overview of the underlying mechanisms in the UK payment industry: how it is structured and governed, who are the key actors, as well as; existing strategic linkages among these actors. The objective of this industrial analysis was to disentangle interorganizational linkages that are required for processing payment transactions throughout different payment infrastructures.

- Intra-Case Analysis: The first author drafted comprehensive case descriptions to outline the business logic underpinning each mobile payment service. Guided by the research questions and theoretical concepts from strategic groups and platform literature, the first author applied content analytical procedures $[34,57]$ to code and interpret the primary interview data in an iterative manner to unpack the logic of mobile payment platforms from an architectural viewpoint $[21,76,79]$. Specifically, the coding is aimed at pinpointing the modular attributes, which constitute the value creation architecture of each platform, and the eventual configuration of strategic linkages with third parties that constitute their value delivery architectures (see Table 2).

- Inter-Case Analysis: Inter-case analysis was performed to enhance the generalizability of our study $[46,79]$. By comparing the cases in terms of their value creation and value delivery architectures, we discovered commonalities and discrepancies among these distinct platform profiles (see Table 2). Particularly, we identified six distinct platform profiles. To ensure the analytical 
consistency of our findings, we applied a differentiated role strategy after the initial data analysis [1]. The first author acted as the primary data collector and coder. The co-authors, on the other hand, played the role of the devil's advocate by putting forth alternative interpretations and counter-arguments. Whenever disagreements surfaced, codes were revisited and discussed until consensus was reached. The entire coding process followed an iterative cycle and data analysis was only completed when all authors agree on the placement of quotes in accordance with the analytical framework.

\section{CASE ANALYSIS: ILLUSTRATIVE MOBILE PAYMENT PLATFORMS}

Platformization has opened the door for mobile payment services to revolutionize how value is created and delivered through interfirm co-innovation. In this section, we present insights gleaned from analyzing the 11 mobile payment platforms. From our data analysis, we identified six platform-driven strategic groups (or platform profiles) within the UK mobile payment market, each with its own innovative approach to configuring its value creation and delivery architectures. Table 3 summarizes the platform profiles derived from our data analysis. We draw on these illustrative case examples to elaborate on the competitive attributes for each platform profile.

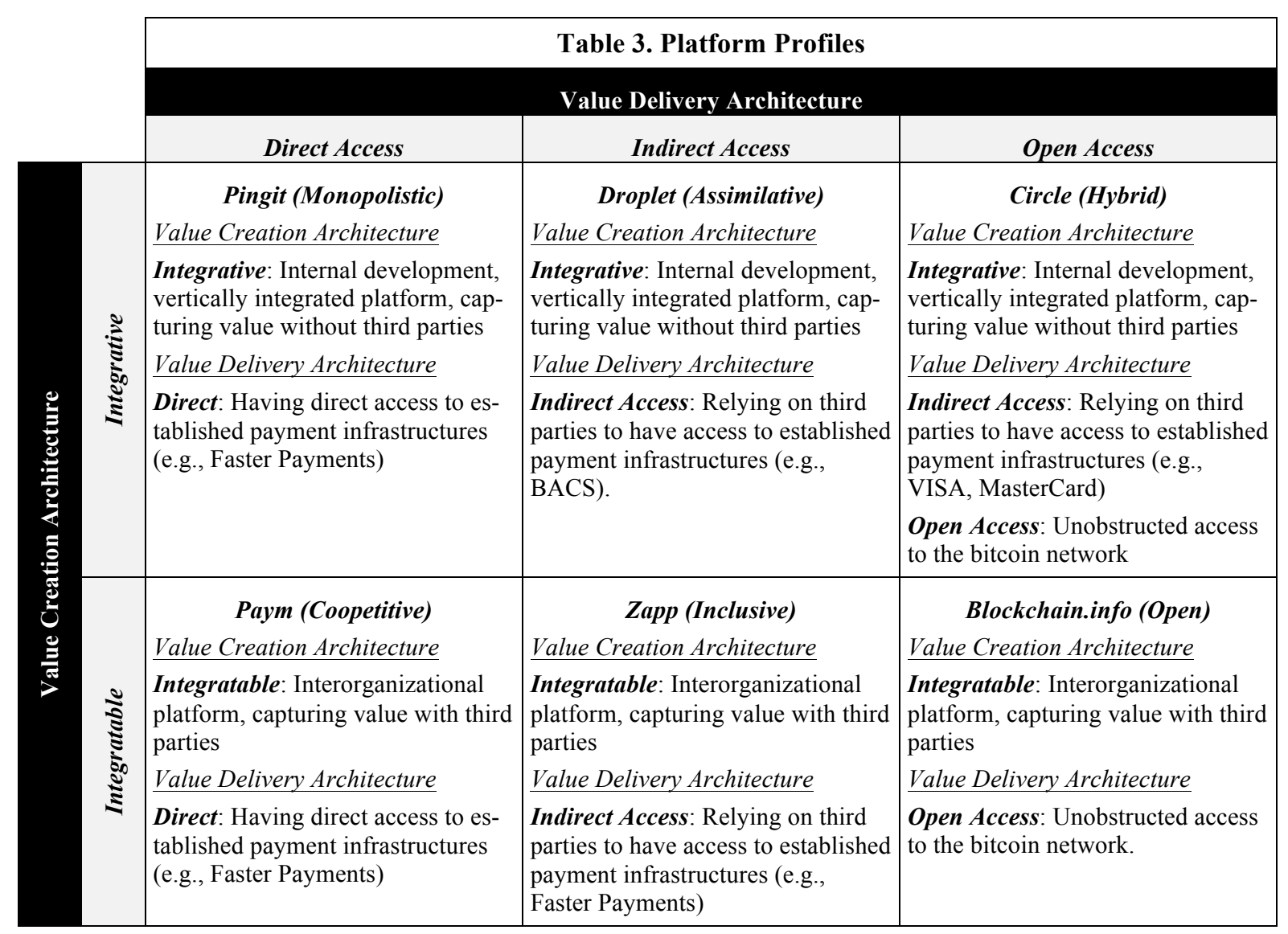

\subsection{Pingit}

In 2012, Barclays launched its own internally-developed mobile payment service: Pingit (Figure 2). Pingit was initially designed to be a person-to-person (P2P) mobile payment service and as a standalone application, it registered solid growth in its user base, which in turn incentivized businesses to adopt Pingit. It is a proprietary mobile payment service as its design and development are fully internalized. As alleged by the Senior Vice President (SVP): “We have a very rapid development cycle ... we're doing a release every month [updates]...so anytime we're adding to those features... we're really adding to the long-term benefit of the product... we have a significant team that's developing and supporting those products or sub-products... under the Pingit umbrella". Additionally, Pingit offers developmental tools 
to approved external developers to build related applications and extend the reach of its value creation architecture: "It has to be, of course, commercially relevant to be disclosing any API's to that party...it's very much about providing information into, or to, the Pingit app as opposed to integrating Pingit into another app...the Techstars [start-up] accelerator program was enormously successful, [the goal is] to have a different set of APIs that kind of the startup app development world can use in a slightly different way" (SVP).

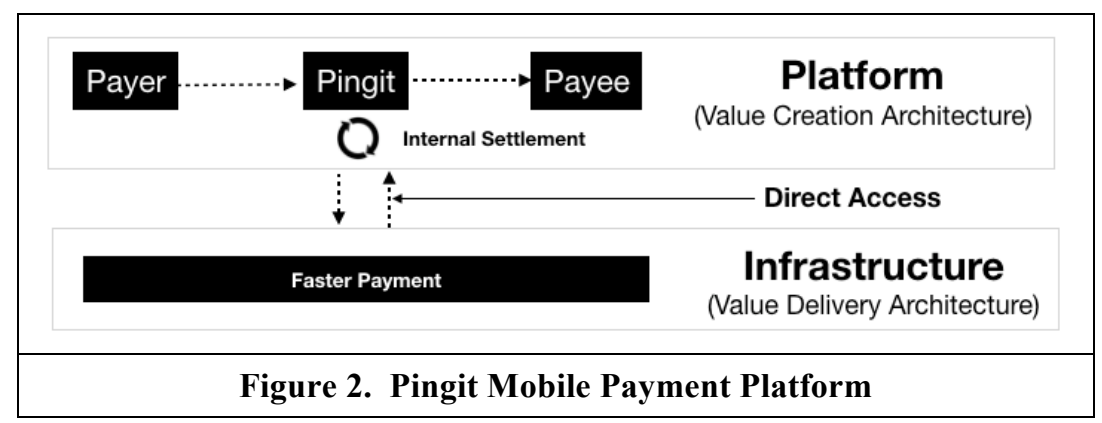

Pingit (see Figure 2) has a dual approach to process payment transactions. For Pingit users (i.e., payers and payees) who are Barclays' customers, the settlement occurs internally within the Pingit platform in real-time. As the SVP elaborated: "A consumer [pushes] the money which is what a Pingit transaction [is] ... we can just move the money from one Pingit account to another". By housing a closed loop system, Pingit harnesses efficiencies from economies of scale by processing transactions internally within its own platform. For Pingit users (i.e., payers and payees) who are not affiliated with Barclays, Pingit is still able to serve them by leveraging on its value delivery architecture. Barclays is a founding member of the Faster Payments scheme that grants Pingit direct access to an established payment infrastructure to process interbank transfers in near real-time. As the SVP remarked: "we use the Faster Payments infrastructure, of course, as one of the founders of the Faster Payments infrastructure we have connectivity".

Value Creation Architecture: Pingit pursues an independent approach to the development of its platform when competing with other mobile payment services. By denying other banking institutions from interfacing with Pingit, Barclays exercises total control over the value creation architecture of its inbuilt platform. But at the same time, Pingit is open to customers from rival banking institutions, who crave a mobile payment solution. As the SVP clarified: "As a competitive bank, [rival banking institutions] can't use Pingit but as a consumer...it's an open market from a consumer perspective...it's our product and our service and we use it as a differentiator from the other banks in the space". Having a large user base, Pingit is also in a comfortable position to dictate its collaborative relationships with external parties, who desire to develop approved platform derivatives for the mobile payment service. In turn, it expands the reach of Pingit's value creation architecture in both service diversity and quality.

Value Delivery Architecture: Through Barclays, Pingit possesses the competitive advantage of having direct access to the Faster Payments payment infrastructure, the dominant value delivery architecture for processing real-time payments. This enables Pingit to serve non-Barclays customers who have bank accounts at rival banking institutions. In this aspect, Barclays' value delivery architecture (i.e., Faster Payments) plays a pivotal role in bolstering the appeal of Pingit to potential customers beyond its own institutional borders.

Monopolistic Platform: By resembling a monopolistic, self-contained mobile payment service on its value creation architecture, Pingit maximizes the value to be gained from its proprietary platform technology. Furthermore, with respect to its value delivery architecture, Pingit has taken advantage of its direct access to an established payment infrastructure (i.e., Faster Payments) to reach out to customers at rival banking institutions in a cost-efficient manner. 


\subsection{Droplet}

Launched in 2012, Droplet (see Figure 3) is a Birmingham-based mobile payment startup that allows small businesses and individuals to perform mobile payment transactions within brick and mortar stores.

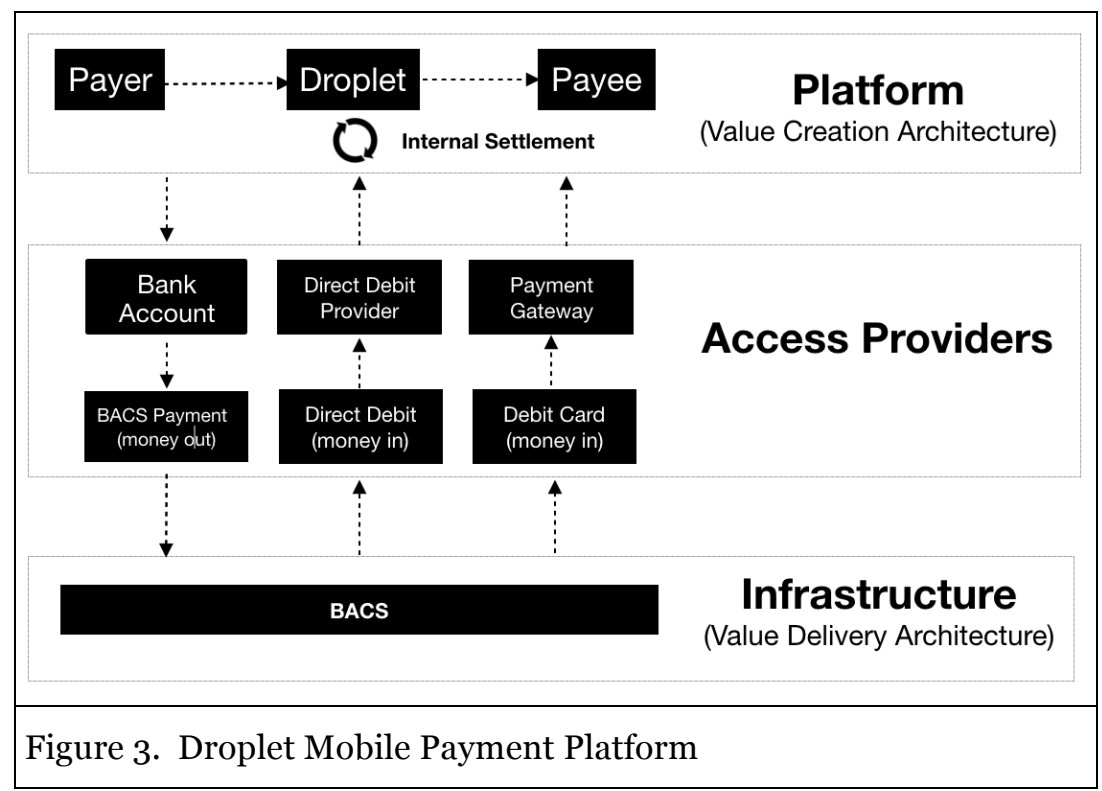

By promoting itself as the 'Skype for payments', Droplet's core value proposition stems from its market position as a free payment service for both payers and payees. Built on standard hardware and open source software, Droplet's standalone application is an internally developed payment service that grants the company absolute control over how its service can be tailored to address market needs. As the Chief Technology Officer (CTO) explained: “The software is Linux, we don't use any Microsoft technologies anywhere in the stack at all...the vast majority of our frameworks are open source, but obviously our [own software] isn't open source". As for granting platform access to external developers, the CTO stated: "We've seen a couple of companies build experimental things on Droplet which has been great and really exciting... but not to the level that we want... without [API keys $\left.{ }^{3}\right]$ it won't work so they need to apply to us for that [API key] ... We can revoke that [API keys] at any time if we want to".

To exploit the full potential of its value creation architecture in facilitating mobile payments between payers and payee, Droplet not only forges strategic linkages with financial institutions whereby payers can top-up their Droplet accounts via direct bank transfers or debit cards linked to their personal bank accounts, but it also offers approved developmental tools (i.e., APIs) to external developers for building their own Droplet-related applications. Through supplying boundary resources (i.e., approved developmental tools) as part of its value creation architecture, Droplet encourages external developers to generate their own platform derivatives with customized business rules to meet the ongoing needs of the market.

With regard to its value delivery architecture, Droplet is dependent on both direct debit providers to withdraw the top-up amount directly from customers' bank accounts (e.g., GoCardless) and payment infrastructure access providers (e.g., Ingenico) for debit card top-ups. As soon as a payment infrastructure access provider receives a top-up request on behalf of Droplet, it will credit the payment into Droplet's bank account. Afterwards, transactions among Droplet customers are instantly settled within its

${ }^{3}$ API keys are authentication codes that must be incorporated into third-party applications to gain access to the developmental tools (i.e., APIs) offered by Droplet. 
internal system. In this way, the money in Droplet's bank account remains untouched during transactions. As the CTO acknowledged: "We are quite insulated from the real world of banking... [payment transactions] can carry on infinitely with no costs to us and no money movement". For those customers who would like to withdraw money from their Droplet accounts and exit the platform, Droplet instructs its bank to send what are known as cost convenient payment batches (i.e., BACS ${ }^{4}$ payment) to the beneficiaries.

Value Creation Architecture: Droplet adheres to an independent approach to the development of its platform to minimize its dependency on external developers. Droplet operates a self-contained mobile payment service that is realized through a blend of self-developed software, inbuilt APIs, and off-theshelf hardware. By pursuing such an approach, Droplet achieves agility in platform development in that it can acquire capabilities externally [69] to respond to fast changing market environments. By housing a closed loop system, Droplet competes through the provision of instantaneous payments that occur within its platform boundaries. This in turn significantly reduces its variable cost structure: "The plan is to grow the system to a scale where more transactions happen inside our economy and reduce our overall reliance on money in and money out...no money is moved at all. This can carry on infinitely with no cost to us and no money movement...so we have merchants in our economy that then buy things from other merchants using their Droplet balance" (CTO).

Value Delivery Architecture: Droplet has indirect access to the BACS payment infrastructure to move money out of its platform. BACS is an established payment infrastructure renowned for its affordability but slow settlement speed. Droplet cooperates with multiple interchangeable access providers to maintain its flexibility. As the CTO admitted: "[These payment providers] are all interchangeable, so if we want to switch suppliers, we switch suppliers and nothing changes [for Droplet]". Consequently, in the absence of direct access to established payment infrastructures, Droplet partners with multiple payment infrastructure access providers to optimize indirect access for its value delivery architecture and acquire efficiency gains for market competition.

Assimilative Platform: Droplet is a self-contained mobile payment service that assimilates external resources to maintain independency on its value creation architecture. Likewise, Droplet's loose coalition with payment infrastructure access providers to indirectly access predominant value delivery architectures gives it the flexibility to depress its cost structure by switching partners when necessary.

\subsection{Paym}

Launched in 2014, Paym (see Figure 4) is a mobile payment service that was initially owned by the UK Payment Council and later by its institutional members. The Payment Council is an industry consortium whose membership encompasses most major British financial institutions (e.g., banks and building societies).

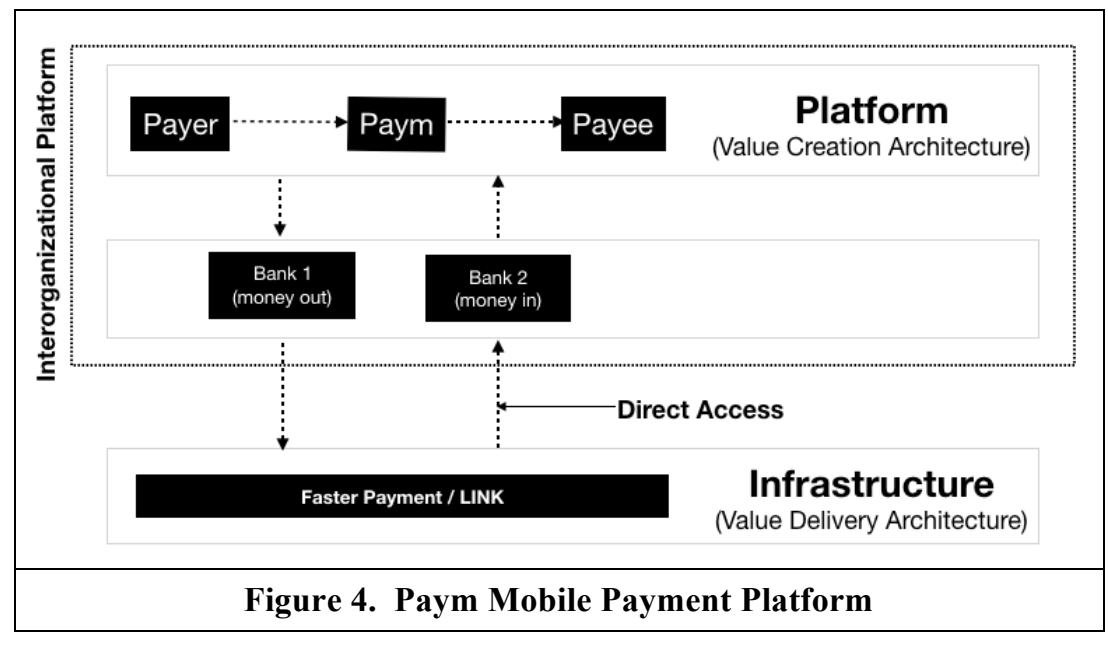

\footnotetext{
${ }^{4}$ Bankers' Automated Clearing Services (BACS) is the payment infrastructure for the clearing and settlement of automated payment methods in the UK such as direct debit.
} 
The Payment Council was inaugurated with a mandate of nurturing the continuous growth of the UK payment industry. Paym is fully developed and operated by an external payment technology provider called Vocalink. Interestingly, Vocalink is also the technology provider for several UK payment infrastructures (e.g., Faster Payments). As alluded to by the Head of Development: "Vocalink [is] our IT provider...we've contracted with Vocalink to provide the database and the associated functionality around it... we went out to tender and Vocalink won the tender and then built the product that we had specified". Born out of the collaboration between the Payment Council and Vocalink, Paym endows UK banking institutions with the capacity to offer mobile payment services to their existing customers. In contrast to Pingit and Droplet, Paym is not a standalone application, but rather operates as a module within existing mobile banking applications developed by institutional members of the Payment Council. Paym hence exists as an interoperable mobile payment service that accommodates diverse banking applications (e.g., HSBC and Santander). In this sense, Paym, unlike Pingit and Droplet, does not exercise control over its value creation architecture by vetting platform derivatives developed by partnering banking institutions. Instead, by positioning itself as a module which can be inserted into existing mobile banking applications, Paym functions as a interorganizational platform to connect Paym-linked bank accounts across partnering banking institutions for processing push payments and accommodate the development of firm-specific platform derivatives.

Paym perpetuates traditional relationships among banking institutions and payment infrastructures (e.g., Faster Payments). The Head of Development mentioned: "The idea is that you already trust your bank, you get this functionality and then everybody can send money to each other using their existing relationship...I'm then providing my bank with the instruction to make a payment and that payment will either go through Faster Payments or it will go through LINK and those are the two approved, two supported, payment schemes in this service".

Value Creation Architecture: Paym pursues a collaborative approach on its value creation architecture to encourage interfirm modularity among banking institutions to develop competitive mobile payment services. Envisioned as an interoperable mobile payment service, the development of Paym has been deliberately subcontracted to an external payment technology provider (i.e., Vocalink) who is familiar with pre-existing interorganizational dependencies among banking institutions and can ensure the interoperability of the platform across a wide range of mobile banking applications. By being highly integratable across heterogeneous banking applications, Paym attains its competitiveness by acting as an inclusive mobile payment service: "The idea is that I can sign up for Paym and I don't need to create a new relationship with a new financial services provider...it's an extension of the functionality that my [mobile banking app] already offers" (Head of Development).

Value Delivery Architecture: Paym, as a mobile payment service offered by the UK banking consortium, has, on its value delivery architecture, direct access to Faster Payments, an established payment infrastructure with real-time processing of financial transactions. Paym thus facilitates regular bank wire transactions so much so that it serves to solidify the current market positions of banking institutions. As the Head of Development asserted: "The bank platform talks directly to Paym and Paym talks directly back to the bank platform ... those are the only connections that exist".

Coopetitive Platform: By integrating into existing mobile banking applications developed by banking institutions that are also engaged in rivalry with one another, Paym competes on its value creation architecture by fueling this rivalry to foster competition in developing firm-specific platform derivatives and better its payment services. Conversely, since banking institutions are already interconnected by having direct access to an established payment infrastructure (i.e., Faster Payments), the competitiveness of Paym on its value delivery architecture is miniscule. 


\subsection{Zapp}

Zapp (see Figure 5) is a mobile payment service owned by the UK payment infrastructure provider, Vocalink.

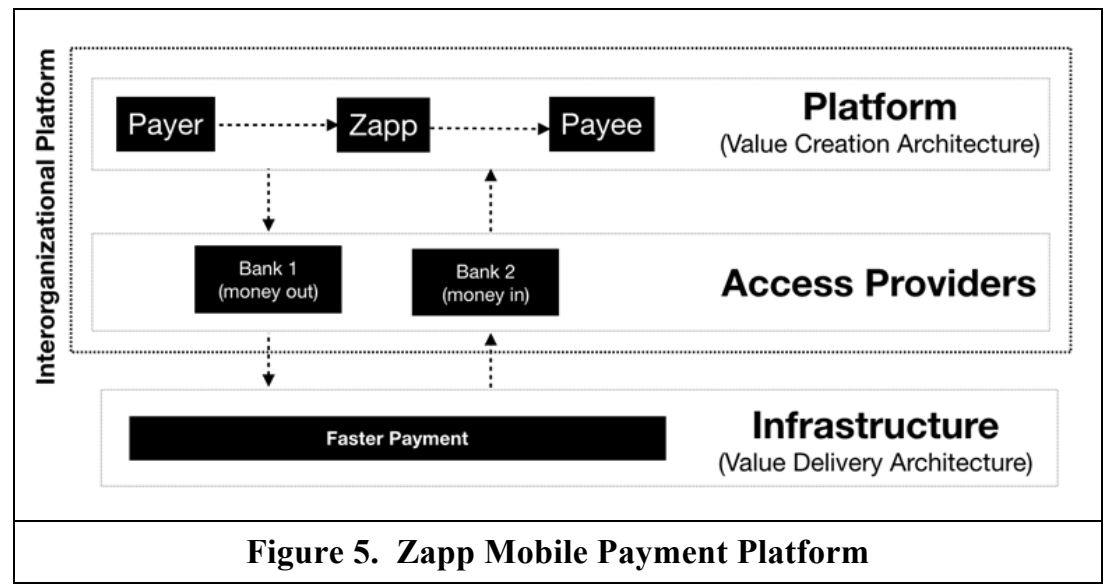

Like the three aforementioned mobile payment solutions, Zapp is designed to facilitate mobile payments between payers and payees. However, for its value creation architecture, Zapp shares commonalities with Paym. Similar to Paym, Zapp's value creation architecture stems from its modularization: it is positioned as a module which can be inserted into existing mobile banking applications. For this reason, Zapp is reliant on contemporary banking partnerships. As the CEO explained: "It's a feature within the [mobile banking] app ... that essentially turns a banks mobile banking app into a vehicle to make payments. So, if you like, we are the messaging service that sits like a scheme between banks on one side and acquirers and merchants on the other side and we manage the flow of information in order to make a payment". To initiate payments, Zapp has only indirect access to the Faster Payments payment infrastructure. In this setup, banks act as proxies to initiate payments on behalf of Zapp between payers' and payees' bank accounts. Not unlike Paym, Zapp reinforces traditional relationships among banking institutions and payment infrastructures. The CEO emphasized that "Zapp works as part of their [mobile banking] app - it's re-intermediating the bank into [customers'] relationship".

Value Creation Architecture: Zapp pursues a collaborative approach on its value creation architecture in that it primarily competes through modularity. It invites banking institutions and other businesses (i.e., merchants) to integrate its modularized mobile payment service into their applications and develop firm-specific platform derivatives. To achieve interoperability and resilience, technology development is developed partially in-house with certain operations being subcontracted to an external vendor (i.e., Oracle). Zapp thus attains competitiveness by being an inclusive mobile payment service that is amenable to a variety of businesses and financial institutions.

Value Delivery Architecture: Zapp has indirect access to the Faster Payments payment infrastructure because it functions primarily as an interorganizational platform to connect bank accounts across banking institutions to form a mobile payment network. Consequently, Zapp configured its strategic linkages with financial institutions in the form of indirect access to an established and fast processing value delivery architecture.

Inclusive Platform: Zapp competes by being an inclusive platform that strives to be readily accessible for various actors in the payment industry (e.g., banking institutions, merchants, and acquirers) by being integratable into external payment systems. Additionally, Zapp is dependent on collaborations to gain indirect access to established value delivery architectures for processing payments. This perpetuates conventional value streams within the payment industry and solidifies the competitive position of current market incumbents. 


\subsection{Blockchain.info}

Founded in 2011, Blockchain.info is a London-based Bitcoin startup that offers three main products: search, bitcoin wallets, and Bitcoin developer tools. Through the free online wallet service, Bitcoin owners can store and transfer them through the Bitcoin network whereas the search engine provides analytics about the status of the network (e.g., recent transactions or volume). The Bitcoin wallet service is targeted towards non-technical users, whereas more adept users utilize Blockchain.info's open APIs. The APIs on this platform permit external developers to integrate the preceding services (e.g., bitcoin wallets or analytics) into their own service offerings. (See Figure 6.)

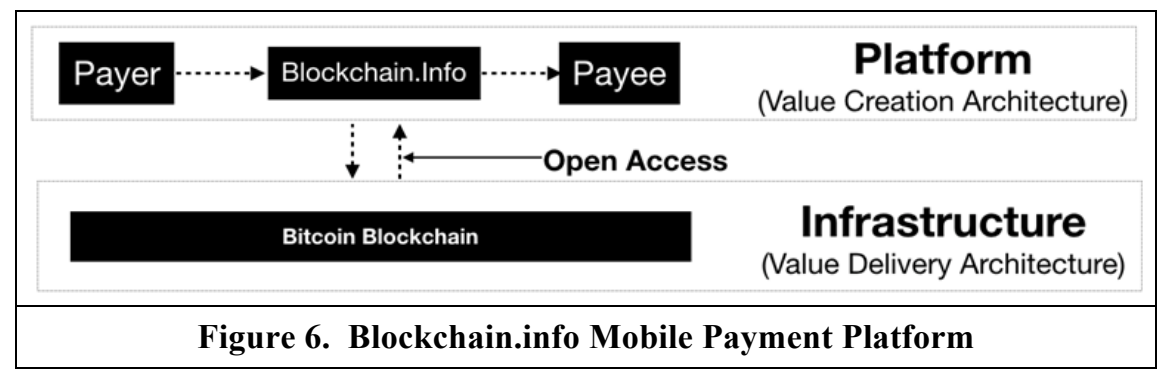

Access to the APIs is open to all. As proclaimed by the co-founder of Blockchain.info: "We are technologists that focus on building APIs that make using Bitcoin protocol simple and easy...our APIs are tool sets for anyone who is impassioned to create innovative [bitcoin] ideas". Referring to its free Bitcoin wallet service: "We serve consumers who want a simple and easy way securely store their Bitcoins, and transact with anyone they want to" (co-founder). Blockchain.info is an independent startup that is not reliant on other technology providers by operating its own local servers. At the same time, the platform is highly open and accessible to external developers by giving them the freedom to integrate parts of Blockchain.info's value creation architecture into their applications. As elaborated by the co-founder, Blockchain.info's APIs are documented and publicly available without restriction: "Our APIs are basically gateways to interface with any type of protocol, so we are highly compatible, we are entirely open, there are no walled gardens" (co-founder).

Value Creation Architecture: Like Paym and Zapp, Blockchain.info also subscribed to an integratable approach for its value creation architecture. Blockchain.info's source code for various services (e.g., Bitcoin wallet) is publicly accessible, thereby providing external developers with the opportunity to review and improve code quality. Moreover, external developers can copy and modify the code in accordance with their needs to create derivative service offerings. By crowdsourcing ideas from its developer community, Blockchain.info is able to improve the quality of its services by collating and integrating these ideas into its own services after an internal review process. As the co-founder stated: "Our lead developer approves pull requests that come from the community and he obviously reviews the code, we go through a testing regiment... and then we release it."

With regards to its hardware, Blockchain.info is, to a large degree, an isolated service because it does not utilize cloud computing (e.g., Amazon AWS). Rather, it operates its own servers to ensure independence and security over customers' Bitcoin deposits. As the co-founder articulated: "From a hardware perspective, we have a large amount of infrastructure, we use dedicated hardware, we never use cloud services... we do that for privacy reasons... [what we are doing], it's very unusual, most people would not do that, they would run hardware by Amazon, and would cost a fraction what we would pay". Software-wise, the co-founder explained: "On the Github repository, we have everything in the public domain and it [is being] constantly used and collaborated upon by people that [are not] Blockchain.info employees".

Value Delivery Architecture: For its value delivery architecture, Blockchain.info depends solely on the Bitcoin network to deliver Bitcoins between payers and payees. As soon as the Bitcoin payment is broadcasted to the Bitcoin network, specialized computers (i.e., Bitcoin miners) around the globe receive transaction requests and verify them through cryptography. These verified transactions are then recorded in a publicly distributed ledger system (i.e., Bitcoin blockchain), which is essentially a P2P book-keeping system of all transactions since the inception of the Bitcoin blockchain. 
Open Platform: Blockchain.info increases its market share by leveraging on external developers and subsidizing its service (e.g., Bitcoin wallets) for customers. In doing so, Blockchain.info, as a platform, derives value from the Bitcoin community by being integratable into various agnostic third-party services. This culminates in positive conditions to reinforce and extend Blockchain.info's competitive position. To deliver Bitcoins throughout the Bitcoin network, Blockchain.info operates on top of the Bitcoin Blockchain, which is an open value delivery architecture without access constraints.

\subsection{Circle}

Founded in 2013, Circle (see Figure 7) is a Boston-based Bitcoin startup that offers mobile payment service in the form of Bitcoin brokerage and free wallets targeted towards end users. Compared to Blockain.info, Circle does not endorse an open developer program that could harness Circle's APIs. With its independent value creation architecture, Circle, has the ambition to transform Bitcoin into an accepted payment currency.

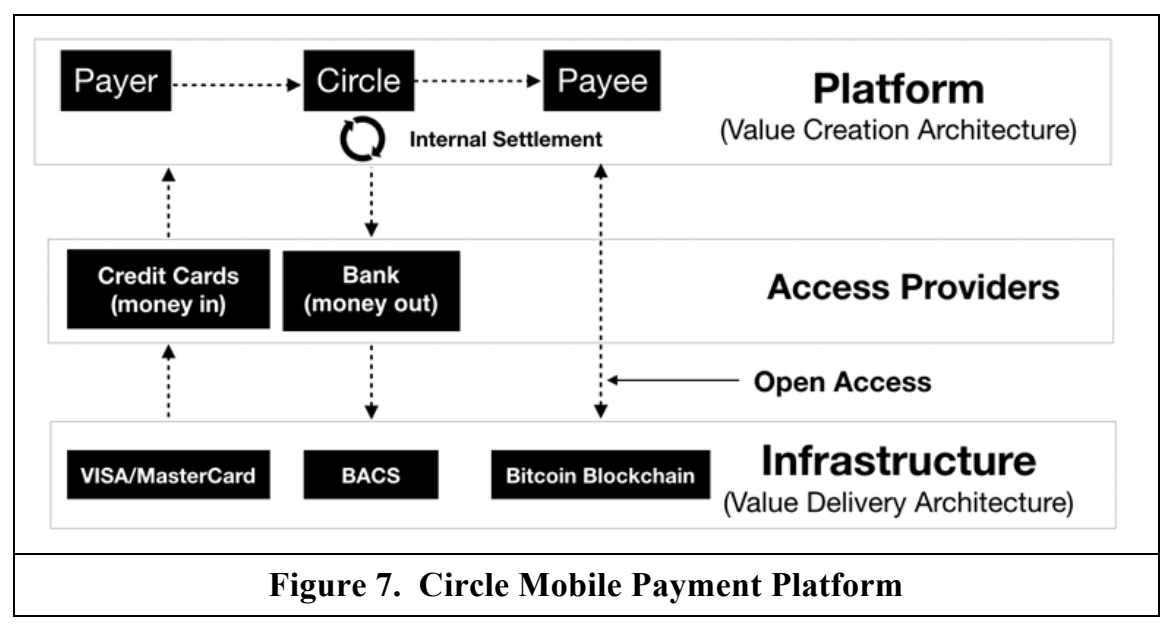

The CEO articulated: "We want to make it easy to store and move value in the same way that people store and share content messages on the Internet...people use [currencies] in everyday life, they are paid in certain currencies and they understand their purchasing power in those currencies, goods and services are priced that way, but we also want that to work globally... in an interoperable way, the way the Internet works, which is...this instant and distributed system that supports the instantaneous movement of data and that is all money is, is just data". Through its e-money license, which requires regulatory compliance (e.g., know your customer (KYC)), Circle, on its value delivery architecture, possesses an advantage of having indirect access to established payment infrastructures. Consequently, in addition to being able to settle transactions among Circle customers instantaneously within its own platform, payments can also be processed through: (1) established payment infrastructures (i.e., VISA and MasterCard), and; (2) the Bitcoin network.

Value Creation Architecture: Circle's value creation architecture is relatively independent as it has the internal resources and capabilities to operate its own payment service, and is not tied to any specialized external resources. As the CEO maintained: "We've build our own digital banking platform from scratch in house, designed around kinds of user experiences that we think that are important for a global person-to-person payment application... we leverage on cloud infrastructure...our core transactional infrastructure of our payment and banking system is all built in house".

Value Delivery Architecture: Circle, on its value delivery architecture, forged strategic linkages to gain access to two separate digital infrastructures: (1) established payment infrastructures (e.g., MasterCard, VISA), and; (2) the Bitcoin network. The CEO claimed that "we want to support ... an open Internet of value and so that's why in addition to integrating into the legacy central banking systems, legacy card networks...we also want to support an open protocol which is the Bitcoin Blockchain".

Hybrid Platform: Circle functions as an independent and hybrid platform that does not rely on interfirm modularity. Furthermore, Circle forged strategic linkages to harness efficiencies from two separate 
value delivery architectures: (1) established payment infrastructures to process transactions in fiat currencies, and; (2) the Bitcoin Blockchain for permissionless global value transfer to emulate direct access rights to an established payment infrastructure.

\section{DISCUSSION}

In networked economies, goods and services are derived from layered modular architectures in the form of digital platforms $[26,64,68,80]$. Digital platforms play a pivotal role in networked economies because they constitute nodes within business networks from which value is concentrated [66]. Because past studies on digital platforms are confronted with conceptual ambiguities and challenges in comparability, de Reuver et al. [16] advanced a research agenda that places emphasis on the importance of a unified vocabulary and comparative analysis when investigating digital platforms.

In this study, we embrace a technological view of digital platforms that dissects mobile payment platforms as layered modular technology architectures [80]. From this viewpoint, we theorized that digital platforms compete through architectural configurations, which strive to generate more value in comparison to their rivals [51]. Specifically, we delineated platforms into value creation and delivery architectures, both of which constitute strategic dimensions pertinent for deciphering competition among mobile payment platforms. Competitive platforms differentiate among themselves through engaging in fintech innovations that emphasize the significance of modular composition and configurations to induce positive network effects within business networks [51,78]. Figure 8 offers an overview of the core findings from our data analysis. By inductively deriving competitive attributes along the strategic dimensions of value creation and value delivery architectures, we arrived at a taxonomy of six platform profiles. Findings suggest that digital platforms compete in the marketplace by being: (1) either integrative or integratable on their value creation architecture, and; (2) having direct, indirect, or open access to pre-existing value delivery architectures to move value among stakeholders within the network.

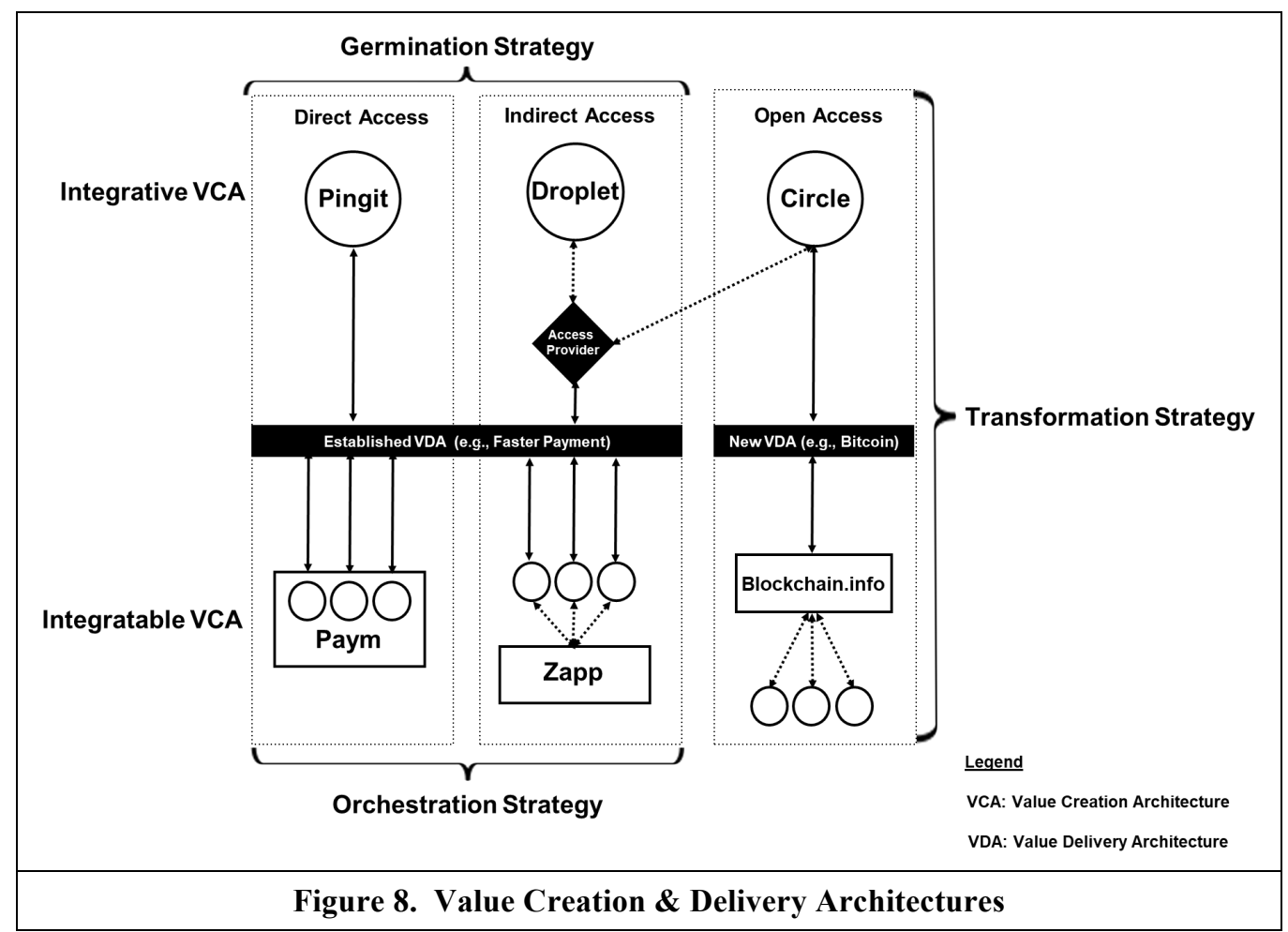




\subsection{Value Creation Architectures: Integrative and Integratable Approaches}

Integrative Approach: Mobile payment platforms (i.e., Circle, Droplet, and Pingit), which subscribes to an integrative approach, can exert control on their value creation architectures at the platform level to co-create value with an exclusive selection of private business partners and shield their services from unauthorized parties. These platforms enact closed loop systems to settle payment transactions within their own boundaries. Settling payment transactions among users within the same payment system is virtually free, instantaneous, and guaranteed. Conversely, sending payments beyond the closed loop system contributes to the cost structure in terms of fees, time, and risk. Integrative platforms tend to assimilate resources and arrange access points in ways that culminate in an inward-looking, verticallyintegrated, and closed-loop ecosystem (see Figure 9).

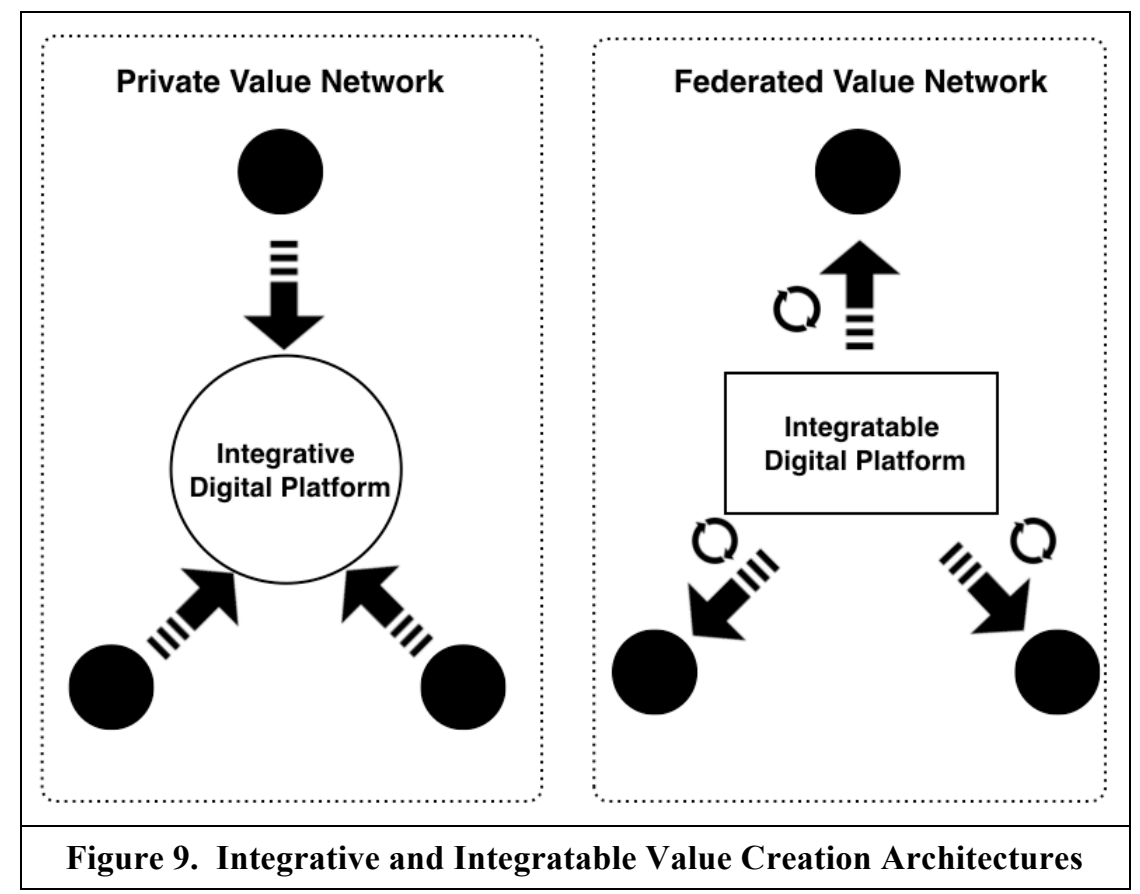

But to reap rewards from economies of scale, integrative mobile payment platform must deliver a compelling service to attain critical mass. From the illustrated cases, all integrative platforms have their own standalone mobile payment service to regulate derivatives being developed on top of their value creation architectures and ensure a consistent user experience. Independence in the value creation architecture allows integrative platforms to be nimble in responding to dynamic markets environments [61]. However, to ensure competitive sustainability, owners of integrative platforms must be sufficiently equipped and adept to continuously nurture their internal developmental capabilities to remain an enticing option for business partners within such private value networks. Otherwise, integrative platforms may have to relinquish their tight control and embrace interfirm modularity to compensate for deficiencies in their value creation architectures. This in turn could dilute their integrative approach to value creation.

Integratable Approach: Platforms with integratable value creation architectures connect and mobilize stakeholders within business networks. The outcome is a mobile payment platform in which the responsibility of value creation and appropriation is distributed among stakeholders within the network (see Figure 9 again). Blockchain.info, Paym, and Zapp exhibit characteristics of integratable platforms in that their services are designed with collaboration in mind and they intentionally co-innovate with external developers to extend the capabilities and market reach of their value creation architecture. Paym's payment feature is designed with the explicit intention of complementing existing mobile banking applications. By integrating Paym's modularized payment service into mobile banking application, Paym connects these mobile banking applications to form an interorganizational mobile payment platform. Likewise, Zapp's value creation architecture, like that of Paym, is designed to be integratable into existing mobile banking applications as a modularized payment service, thereby leading to the formation 
of an interorganizational mobile payment platform. Conversely, even though Blockchain.info has its own standalone applications targeted towards customers, Blockchain.info's mobile payment service is highly attractive for third parties (e.g., business startups) because it is designed to be integratable into their existing applications without the need for permission. Platforms with integratable value creation architectures modularize and exploit interorganizational resources to co-create value within an orchestrated business network. We define the structure from platforms taking such a collaborative approach as a federated value network.

On a cautionary note, an interorganizational platform encounters challenges from reduced control, increased transaction costs, misalignment between business and IT, as well as intense rivalry among stakeholders. In other words, if the costs of maintaining integratable platforms outweigh the benefits of cultivating interorganizational collaboration, owners of such platforms may be inclined to turn to an integrative approach to achieve flexibility in responding to business opportunities.

\subsection{Value Delivery Architectures: Three Modes of Access}

Direct Access: Mobile payment platforms with direct access to established value delivery architectures are often able to profit from these industry-specific resources (see Figure 10). Pingit (Barclays) and Paym, which have unobstructed access to established payment infrastructures, compete by exploiting their direct access rights to deliver guaranteed and instantaneous mobile payment services via these value delivery architectures. Direct transactions delivered through Pingit and Paym reinforce their direct access rights, their status as payment platforms, and ultimately their contemporary market positions. Direct access to established value delivery architectures, which offer the greatest possible market reach within an economy, is tantamount to a valuable configuration of strategic linkages that cannot be emulated by competing platforms readily.

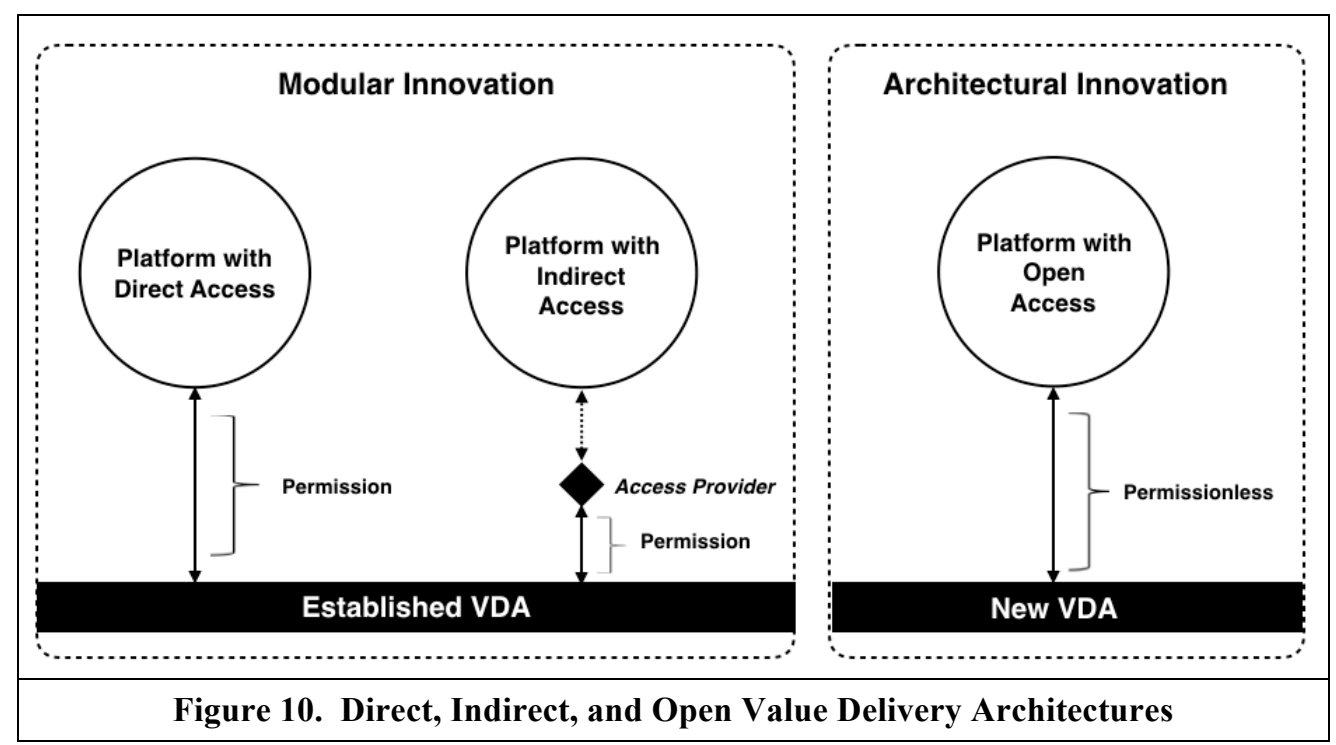

Nonetheless, direct access comes with the burden of costly maintenance (e.g., monthly fix and variable costs) as well as extensive coordination between platform and infrastructure owners. Moreover, such value delivery architectures, being critical national infrastructures, are heavily regulated. Direct access owners (e.g., banking institutions) are legally obliged to offer non-discriminatory indirect access to rival institutions. To overcome this disadvantage, integrative payment platforms with direct access (e.g., Pingit) attempt to reduce direct access challenges by creating their own vertically-integrated, closed loop mobile payment system to settle payment transactions within its own boundaries. Transactions settled within integrative platforms suppress variable costs. For financial institutions that have direct access but do not possess the competency to develop an integrative platform (e.g., Paym), they join up with owners of interoperable mobile payment services (or interorganizational platforms) to achieve competitiveness and customers relevance. The downside is that such an arrangement demands costly direct access for each transaction to serve customers at other financial institutions even though these institutions operate on the same interorganizational platform. This in turn adds to the variable cost 
structure.

Indirect Access: Mobile payment platforms with indirect access to established value delivery architectures achieve competitiveness by cooperating with third parties (e.g., banking institutions) offering the best indirect access conditions (see Figure 10 again). In our study, Droplet and Zapp do not possess direct access rights. To compensate for the lack of this industry-specific resource, both platforms forged strategic linkages with third parties. For instance, Droplet is versatile by partnering with multiple financial intermediaries. Droplet applies a plug-and-play strategy in selecting interchangeable intermediaries that offer the most economical indirect access options. Zapp, on the other hand, formed hard-to-replicate strategic linkages with banking institutions that have privileged direct access rights to established payment infrastructures.

Challenges associated with indirect access stem from platforms' dependency on third parties and ongoing transaction costs that accompany each usage, alteration, and adjustment of the value delivery architecture. This also implies that third parties can impose constraints on mobile payment platforms whenever a transaction is initiated that requires access to established payment infrastructures. To outweigh these costs and ensure competitiveness, integratable mobile payment platforms with indirect access (e.g., Zapp) forged strategic linkages with select third parties in the business network that has the furthest market reach and can guarantee real-time processing of payments. Alternatively, integrative platforms with indirect access (e.g., Droplet) harness their internal capabilities to create a complementary closed loop system that emulates direct access attributes (i.e., instant and guaranteed payments). This way, platforms with indirect access can circumvent the restrictions of slow value delivery architectures (e.g., BACS) when sending payments across financial institutions.

Open Access: Mobile payment platforms with open access achieve competitiveness by leveraging novel value delivery architectures (e.g., Bitcoin blockchain). Open access endeavors to emulate direct access rights (i.e., unobstructed payment without intermediaries) in a cost-effective fashion (see Figure 10). Nevertheless, new value delivery architectures do not have the same market reach as that of established ones nor have they been comprehensively tested. To overcome this, Circle incorporates both indirect and open access to simultaneously access the fiat money network and also service customers within the Bitcoin network. Still, Circle's indirect access comes with its own costs. To maintain indirect access to established payment infrastructures and sustain partnerships with incumbent financial institutions, Circle must invest in internal resources to comply with national laws (e.g., anti-money laundering). This is because customers who transact purely within the Bitcoin network are normally not identifiable due to Bitcoin's permissionless and pseudonymous nature.

Blockchain.info does not possess connectivity to established payment infrastructures. Besides, Blockchain.info has no intention of leveraging on pre-existing value delivery architectures because it aims to acquire a dominant position within the Bitcoin network. To accomplish this, Blockchain.info is highly integratable on its value creation architecture while facilitating third part transactions through open access over its value delivery architecture (i.e., Bitcoin blockchain). However, Blockchain.info faces hurdles in that the Bitcoin network, at the time of writing, is still in its infancy with unproven business processes and competing technological standards. Consequently, it cannot match up to pre-existing value delivery architectures in terms of its speed, reliability, and market reach.

\subsection{Three Types of Platform Competition Strategies}

Germination Strategy: Monopolistic and assimilative platform profiles resonate with what we label as the strategy of germination. The germination strategy allows firms to cultivate and grow private business networks by capturing value without intervention from third parties at the platform level. In this sense, value streams are tightly controlled and directed inwards to reinforce an insular platform. Pingit (Monopolistic) and Droplet (Assimilative) possess the resources and capabilities to implement a selfsustaining platform by shielding their value creation architecture from third parties. For their value delivery architectures, both platforms showcase high independency and flexibility in channeling their value outputs (i.e., payments) through pre-existing value delivery architectures. The challenge here is to maintain agility by avoiding the enactment of strategic linkages with partners that will introduce long term legacy systems or platform derivatives on their value creation architectures. With regards to value 
delivery architectures, the germination strategy has an ambivalent relationship. Platforms rely on both direct and indirect access to value delivery architectures to process transactions, while at the same time, reduce their outflow as much as possible to reduce costs. Continuous payment outflows could undermine the germination strategy of platforms.

Orchestration Strategy: Platforms with coopetitive and inclusive profiles adhere to what we label as the orchestration strategy. In this regard, Paym (Coopetitive) and Zapp (Inclusive) designed their platforms to be highly integratable with existing mobile banking applications. The challenge of an orchestration strategy is to derive a value creation architecture that aligns the business and technology interests among platform stakeholders. For value delivery, the orchestration strategy is highly dependent on established value delivery architectures to connect stakeholders and attain high levels of joint market reach. However, each transaction on pre-existing value delivery architectures contributes to the cost structure for each platform stakeholder even though they belong to the same mobile payment service.

Transformation Strategy: Platforms with hybrid (Circle) and open (Blockchain.info) profiles reverberate with what we label as the transformation strategy. Transformations within technology industries are mainly driven by two factors: product and processes innovations [75]. Tushman and Anderson [75] argued that for non-assembled goods (i.e., commodities), process innovation is more critical as compared to product innovation. In this study, platforms with transformation strategy embrace process innovation to deliver payments through differentiated and cost-effective arrangements. This is realized through forging strategic linkages with novel value delivery architectures (i.e., Bitcoin blockchain). In this regard, Blockchain.info and Circle attempt to introduce architectural innovation in the mobile payments market. Particularly, both companies can circumvent the dominance of pre-existing value delivery architectures even though novel value delivery architectures, in the likes of Blockchain, bear the risk of failing to become a dominant standard in value movement.

\subsection{Implications for Theory and Practice}

In conclusion, this study touches on how fintech in the likes of mobile payment services have leveraged on digital platformization to revolutionize their value creation and delivery architectures. Digital platformization has also provided opportunities for new financial service providers to free themselves from traditional financial institutions such as banks by altering how these mobile payment services compete with one another. This study thus contributes to extant literature on digital platform competition on three fronts. First, we performed a comparative analysis of mobile payment services in the UK market to inductively derive attributes along the two strategic dimensions of value creation and delivery architectures through which these fintech innovate to compete with one another. From these attributes, we classify mobile payment services into six distinct platform profiles and articulate the competitive strategy associated with each profile. One of the key findings for this study is that the competitiveness of digital platforms is dictated by their competitive attributes, as derived from firm-specific resources and capabilities, along the two focal dimensions of value creation and delivery architectures. Specifically, the study identifies two competitive attributes (i.e., integrative and integratable) for the dimension of value creation architecture and three competitive attributes (i.e., direct, indirect, and open) for the dimension of value delivery architecture in determining the platform profile. In turn, the interplay between these two strategic dimensions shape platform strategy, leading to either germination, orchestration, or transformation strategy in relation to how these fintech seek to redefine their competitive landscape.

By adopting mobile payment services as our empirical context, this study contributes to extant literature on platform and strategic management by uncovering the direction of value streams and explicating how such value streams can be appropriated by these fintech. Specifically, integrative platforms tend to internalize value from private business networks by shielding themselves from third parties. Conversely, integratable platforms extract value from federated business networks by promoting the development of interorganizational platform derivatives in a reciprocal manner.

Lastly, this study extends prior research on innovation by showcasing how fintech innovations, when coupled with digital platforms, can support an ambidextrous approach towards innovation. As is evident from the case of Circle, the modularity of platforms enables these fintech to revolutionize the competitive landscape on two fronts concurrently. One, such platforms facilitate modular innovation on the value delivery architecture to sustain the logic of established payment infrastructures. Two, such digital 
platforms can culminate in architectural innovation in the same technology stack, which in turn could culminate in the replacement of pre-existing value delivery architectures with new ones (e.g., Bitcoin blockchain). Successful architectural innovation has the potential of delivering significant competitive advantage over market incumbents as it destroys the basis of their competitiveness, namely direct access to established payment infrastructures in the context of mobile payments market.

From a practitioner viewpoint, we not only support strategic planning on the part of platform owners by increasing their awareness for critical reflections of their architectural configurations and potential business partners, but we also inform policy makers in drafting legislative frameworks to foster innovation in the current revolutionary fintech landscape. This paper is constrained in its generalizability, as the case studies were conducted in the UK mobile payments market. These limitations translate into future research avenues for replicating our study in other platform-driven markets to validate and refine our taxonomy of platform profiles beyond the UK mobile payments market.

\section{Brief Bios of the Authors}

Erol Kazan is a PhD candidate at the Department of Digitalization, Copenhagen Business School, Denmark. His current research focuses on digital platforms and financial technology in the area of cryptocurrencies and blockchain. His research has been presented at numerous international conferences and published in peer-reviewed journals such as Communications of the Association for Information Systems and Journal of Theoretical and Applied Electronic Commerce Research.

Chee-Wee Tan is a Professor in the Department of Digitalization at Copenhagen Business School. His primary research interests center on design and innovation issues related to the delivery of digital services in various contexts such as e-business, e-commerce, e-government, e-health, e-marketplace and $\mathrm{m}$-commerce. His research has been published in leading peer-reviewed journals including MIS Quarterly, Information Systems Research, European Journal of Information Systems, Journal of the American Society for Information Science and Technology, Information \& Management and Decision Support Systems, among others. Chee-Wee currently serves as an Associate Editor for MIS Quarterly, Internet Research and Journal of Management Analytics as well as on the Editorial Board of Industrial Management and Data Systems and IEEE Transactions on Engineering Management. He is a past recipient of the Outstanding Associate Editor Award for services rendered to MISQ.

Eric T.K. Lim is a tenured Senior Lecturer in the School of Information Systems \& Technology Management at UNSW Business School, UNSW Sydney. Eric is interested in investigating phenomena on how technologically enabled open innovations in the likes of crowd platforms and social media can be harnessed to benefit society. Apart from being a regular presenter at prestigious international conferences, findings from Eric's research has also been published in leading academic journals such as Information Systems Research, Journal of the American Society for Information Science and Technology, European Journal of Information Systems and Decision Support Systems among others. Eric currently serves as an Associate Editor for Internet Research.

Carsten Sørensen is Associate Professor (Reader) in Digital Innovation within Department of Management at The London School of Economics and Political Science. Since the 1980s, he has researched digital innovation, for example, innovating the digital enterprise through mobile technology, and the innovation dynamics of mobile infrastructures and platforms. Carsten has published widely within Information Systems since 1989, for example, in MIS Quarterly, Information Systems Research, Information Systems Journal, Journal of Information Technology, Information \& Organization, The Information Society, Computer Supported Cooperative Work, and Scandinavian Journal of Information Systems. Carsten has been engaged in assisting and assessing digital startups and has been actively engaged in academic consultancy and executive education with a broad range of organisations - IMF, Microsoft, Google, PA Consulting, Orange, Vodafone, Intel, GEMS, to name just a few.

Jan Damsgaard is Head of the Department of Digitalization, Copenhagen Business School, Denmark. $\mathrm{He}$ holds a PhD in Information Systems and a Master of Science degree in Computer Science. His research focuses, in general, on digitalization and disruption and in particular on the diffusion and implementation of networked technologies such as payment services, social media, and platform services. 
His work combines business and technological perspectives. The application domain is often the finance, IT and transportation sector. He has worked and done research at numerous institutions in Denmark, USA, China, Finland, and Australia.

\section{REFERENCES}

1. Adler, P.A., and Adler, P. Intense loyalty in organizations: A case study of college athletics. Administrative Science Quarterly, 33, 3 (1998), 401-417.

2. Adner, R., and Kapoor, R. Value creation in innovation ecosystems: How the structure of technological interdependence affects firm performance in new technology generations. Strategic Management Journal 31, 3 (2010), 306-333.

3. Adner, R. Match your innovation strategy to your innovation ecosystem. Harvard Business Review, 84, 4 (2006), 98.

4. Ahuja, G. The duality of collaboration: Inducements and opportunities in the formation of interfirm linkages. Strategic Management Journal 21, 3 (2000), 317-343.

5. Bharadwaj, A., El Sawy, O.A., Pavlou, P.A., and Venkatraman, N. Digital business strategy: toward a next generation of insights. MIS Quarterly, 37, 2 (2013), 471-482.

6. Bogner, W.C., Thomas, H., and McGee, J. A longitudinal study of the competitive positions and entry paths of European firms in the U.S. pharmaceutical market. Strategic Management Journal, 17, 2 (1996), 85-107.

7. Boudreau, K.J. Let a thousand flowers bloom? An early look at large numbers of software app developers and patterns of innovation. Organization Science, 23, 5 (2012), 1409-1427.

8. Boudreau, K.J. Open platform strategies and innovation: Granting access vs. devolving control. Management Science 56, 10 (2010), 1849-1872.

9. Bresnahan, T.F. and Greenstein, S. Technological competition and the structure of the computer industry. The Journal of Industrial Economics, 47, 1 (1999), 1-40.

10. Ceccagnoli, M., Forman, C., Huang, P., and Wu, D.J. Co-creation of value in a platform ecosystem: The case of enterprise software. MIS Quarterly, 36, 1 (2012), 263-290.

11. Chakravorti, S., and Roson, R. Platform competition in two-sided markets: The case of payment networks. Review of Network Economics, 5, 1 (2006).

12. Cool, K., and Dierickx, I. Rivalry, strategic groups and firm profitability. Strategic Management Journal, 14, 1 (1993), 47-59.

13. Cui, A.S., Calantone, R.J., and Griffith, D.A. Strategic change and termination of interfirm partnerships. Strategic Management Journal, 32, 4 (2011), 402-423.

14. Dahlberg, T., Guo, J., and Ondrus, J. A critical review of mobile payment research. Electronic Commerce Research and Applications, 14, 5 (2015), 265-284.

15. de Reuver, M., and Ondrus, J. When technological superiority is not enough: The struggle to impose the SIM card as the NFC secure element for mobile payment platforms. Telecommunications Policy, 41, 4 (2017), 253-262.

16. de Reuver, M., Sørensen, C., and Basole, R.C. The digital platform: a research agenda. Journal of Information Technology, (2016), 1-12.

17. de Reuver, M., Verschuur, E., Nikayin, F., Cerpa, N., and Bouwman, H. Collective action for mobile payment platforms: A case study on collaboration issues between banks and telecom operators. Electronic Commerce Research and Applications, 14, 5 (2015), 331-344.

18. DeSarbo, W.S., and Grewal, R. Hybrid strategic groups. Strategic Management Journal, 29, 3 (2008), 293-317.

19. Dyer, J.H., and Singh, H. The relational view: Cooperative strategy and sources of interorganizational competitive advantage, Academy of Management Review, 23, 4 (1998), 660679

20. Eaton, B., Elaluf-Calderwood, S., Sørensen, C., and Yoo, Y. Distributed tuning of boundary resources: The case of Apple's iOS service system. MIS Quarterly, 39, 1 (2015), 217-243.

21. Eisenhardt, K.M. Building theories from case study research. Academy of Management Review, 14, 4 (1989), 532-550.

22. Eisenmann, T., Parker, G., and Van Alstyne, M. Platform envelopment. Strategic Management 
Journal, 32, 12 (2011), 1270-1285.

23. El Sawy, O.A., Malhotra, A., Park, Y., and Pavlou, P.A. Research commentary-seeking the configurations of digital ecodynamics: It takes three to tango. Information Systems Research, $21,4(2010), 835-848$.

24. Ferguson, T.D., Deephouse, D.L., and Ferguson, W.L. Do strategic groups differ in reputation? Strategic Management Journal, 21, 12 (2000), 1195-1214.

25. Fiegenbaum, A., and Thomas, H. Strategic groups as reference groups: Theory, modeling and empirical examination of industry and competitive strategy. Strategic Management Journal, 16, 6 (1995), 461-476.

26. Gawer, A., and Cusumano, M.A. Industry platforms and ecosystem innovation. Journal of Product Innovation Management, 31, 3 (2014), 417-433.

27. Ghazawneh, A., and Henfridsson, O. Balancing platform control and external contribution in third-party development: The boundary resources model. Information Systems Journal, 23, 2 (2013), 173-192.

28. González-Moreno, Á., and Sáez-Martínez, F. Rivalry and strategic groups: What makes a company a rival? Journal of Management \& Governance, 12, 3 (2008), 261-285.

29. Gregor, S. The nature of theory in information systems. MIS Quarterly, 30, 3 (2006), 611-642.

30. Gulati, R., Nohria, N., and Zaheer, A. Strategic networks. Strategic Management Journal, 21, 3 (2000), 203-215.

31. Hanseth, O., and Lyytinen, K. Design theory for dynamic complexity in information infrastructures: the case of building internet. Journal of Information Technology, 25, 1 (2010), $1-19$.

32. Hedman, J., and Henningsson, S. The new normal: Market cooperation in the mobile payments ecosystem. Electronic Commerce Research and Applications, 14, 5 (2015), 305-318.

33. Henfridsson, O., and Bygstad, B. The generative mechanisms of digital infrastructure evolution. MIS Quarterly, 37, 3 (2013), 907-931.

34. Hsieh, H.F., and Shannon, S.E. Three approaches to qualitative content analysis. Qualitative Health Research, 15, 9 (2005), 1277-1288.

35. Hunt, M. Competition in the major home appliance industry. Thesis, Harvard University, Boston, 1972.

36. Karimi, J., and Walter, Z. The role of dynamic capabilities in responding to digital disruption: A factor-based study of the newspaper industry. Journal Management Information Systems, 32, 1 (2015), 39-81.

37. Koruna, S. Leveraging knowledge assets: Combinative capabilities-theory and practice. $R \& D$ Management, 34, 5 (2004), 505-516.

38. Kumar, R.L. A framework for assessing the business value of information technology infrastructures. Journal of Management Information Systems, 21, 2 (2004), 11-32.

39. Lee, G., and. Raghu, T.S. Determinants of mobile apps' success: Evidence from the app store market, Journal of Management Information Systems, 31, 2 (2014), 133-170.

40. Lee, J., Lee, K., and Rho, S. An evolutionary perspective on strategic group emergence: A genetic algorithm-based model. Strategic Management Journal 23, 8 (2002), 727-746.

41. Mantena, R., and Saha, R.L. Co-opetition between differentiated platforms in two-sided markets. Journal of Management Information Systems, 29, 2 (2012), 109-140.

42. Mas-Ruiz, F.J., Ruiz-Moreno, F., and Ladrón de Guevara Martínez, A. Asymmetric rivalry within and between strategic groups. Strategic Management Journal, 35, 3 (2014), 419-439.

43. Mascarenhas, B., and Aaker, D.A. Mobility barriers and strategic groups. Strategic Management Journal, 10, 5 (1989), 475-485.

44. McGee, J., and Thomas, H. Strategic groups: Theory, research and taxonomy. Strategic Management Journal, 7, 2 (1986), 141-160.

45. Mehra, A. Resource and market based determinants of performance in the U.S. banking industry. Strategic Management Journal, 17, 4 (1996), 307-322.

46. Miles, M.B., and Huberman, A.M. Qualitative Data Analysis: An Expanded Sourcebook. London: Sage, 1994.

47. Nohria, N., and Garcia-Pont, C. Global strategic linkages and industry structure. Strategic Management Journal, 12, S1 (1991), 105-124. 
48. Ondrus, J., and Pigneur, Y. An assessment of NFC for future mobile payment systems. In Proceedings of the International Conference on the Management of Mobile Business, Los Alamitos, CA: IEEE Computer Society Press, 2007, pp. 43-52.

49. Ondrus, J., Gannamaneni, A., and Lyytinen, K. The impact of openness on the market potential of multi-sided platforms: A case study of mobile payment platforms. Journal of Information Technology, 30, 3 (2015), 260-275.

50. Ozcan, P., and Santos, F.M. The market that never was: Turf wars and failed alliances in mobile payments. Strategic Management Journal, 36, 10 (2015), 1486-1512.

51. Pagani, M. Digital business strategy and value creation: Framing the dynamic cycle of control points. MIS Quarterly, 37, 2 (2013), 617-632.

52. Pegels, C.C., Song, Y.I., and Yang, B. Management heterogeneity, competitive interaction groups, and firm performance. Strategic Management Journal, 21, 9 (2000), 911-923.

53. Peteraf, M. The cornerstones of competitive advantage: A resource-based view. Strategic Management Journal, 14, 3 (1993), 179-191.

54. Pil, F.K., and Cohen, S.K. Modularity: Implications for imitation, innovation, and sustained advantage. Academy of Management Review, 31, 4 (2006), 995-1011.

55. Popper. N. Bitcoins start-up gets an electronic money license in Britain. Dealbook, New York Times (April 6, 2016).

56. Porter, M.E. Competitive Strategy: Techniques for Analyzing Industries and Competitors. New York: FreePress, 1980.

57. Potter, W.J., and Levine-Donnerstein, D. Rethinking validity and reliability in content analysis. Journal of Applied Communication Research, 27, 3 (1999), 258-284.

58. Reger, R.K., and Huff, A.S. Strategic groups: A cognitive perspective. Strategic Management Journal, 14, 2 (1993), 103-123.

59. Rochet, J.C., and Tirole, J. Cooperation among competitors: Some economics of payment card associations. Rand Journal of Economics, 33, 4 (2000), 549-570.

60. Rochet, J.C., and Tirole, J. Platform competition in two-sided markets. Journal of the European Economic Association, 1, 4 (2003), 990-1029.

61. Sambamurthy, V., Bharadwaj, A., and Grover, V. Shaping agility through digital options: Reconceptualizing the role of information technology in contemporary firms. MIS Quarterly, 27, 2 (2003), 237-263.

62. Sarker, S., Sarker, S.. Sahaym, A., and Bjørn-Andersen, N. Exploring value cocreation in relationships between an ERP vendor and its partners: A revelatory case study. MIS Quarterly, 36, 1 (2012), 317-338.

63. Schierz, P.G., Schilke, O., and Wirtz, B.W. Understanding consumer acceptance of mobile payment services: An empirical analysis. Electronic Commerce Research and Applications, 9, 3 (2010), 209-216.

64. Schilling, M.A. Toward a general modular systems theory and its application to interfirm product modularity. Academy of Management Review, 25, 2 (2000), 312-334.

65. Short, J.C., Ketchen, D.J., Palmer, T.B., and Hult, G.T.M. Firm, strategic group, and industry influences on performance. Strategic Management Journal, 28, 2 (2007), 147-167.

66. Stabell, C.B., and Fjeldstad, Ø.D. Configuring value for competitive advantage: On chains, shops, and networks. Strategic Management Journal, 19, 5 (1998), 413-417.

67. Star, S.L., and Ruhleder, K. Steps toward an ecology of infrastructure: Design and access for large information spaces. Information Systems Research, 7, 1 (1996), 111-134.

68. Staudenmayer, N., Tripsas, M., and Tucci, C.L. Interfirm modularity and its implications for product development. Journal of Product Innovation Management, 22, 4 (2005), 303-321.

69. Teece, D.J., Pisano, G., and Shuen, A. Dynamic capabilities and strategic management. Strategic Management Journal, 18, 7 (1997), 509-533.

70. Thomas, H., and Venkatraman, N. Research on strategic groups: progress and prognosis. Journal of Management Studies, 25, 6 (1998), 537-555.

71. Thomas, L., Autio, E., and Gann, D. Architectural leverage: Putting platforms in context. Academy of Management Perspective, 28, 2 (2014), 198-219.

72. Tilson, D., Lyytinen, K., and Sørensen, C. Research commentary-Digital infrastructures: The missing IS research agenda. Information Systems Research, 21, 4 (2010), 748-759. 
73. Tiwana, A. Platform desertion by app developers. Journal of Management Information Systems, 32, 4 (2015), 40-77.

74. Tiwana, A., Konsynski, B., and Bush, A.A. Research commentary-platform evolution: Coevolution of platform architecture, governance, and environmental dynamics. Information Systems Research, 21, 4 (2010), 675-687.

75. Tushman, M.L., and Anderson, P. Technological discontinuities and organizational environments. Administrative Science Quarterly, 31, 3 (1986), 439-465.

76. Walsham, G. Interpretive case studies in IS research: Nature and method. European Journal of Information Systems, 4, 2 (1995), 74-81.

77. West, J. How open is open enough? Melding proprietary and open source platform strategies. Research Policy, 32, 7 (2003), 1259-1285.

78. Woodard, C.J., Ramasubbu, N., Tschang, F.T., and Sambamurthy, V. Design capital and design moves: The logic of digital business strategy. MIS Quarterly, 37, 2 (2013), 537-564.

79. Yin, R.K. Case Study Research: Design and Methods. London: Sage, 2009.

80. Yoo, Y., Henfridsson, O., and Lyytinen, K. Research commentary-The new organizing logic of digital innovation: An agenda for information systems research. Information Systems Research, 21, 4 (2010), 724-735.

81. Zittrain, J.L. The generative Internet. Harvard Law Review, 119,7 (2006), 1974-2040. 